\title{
Reactions of Ruthenium Cyclopentadienyl Praecursor in the Metal Precursor Pulse of Ru Atomic Layer Deposition
}

\author{
Ji Liu ${ }^{\mathrm{a}}$, Hongliang Lu ${ }^{\mathrm{b}}$, David Wei Zhang ${ }^{\mathrm{b}}$, and Michael Nolan ${ }^{\mathrm{a}, \mathrm{c}^{*}}$ \\ ${ }^{a}$ Tyndall National Institute, University College Cork, Lee Maltings, Dyke Parade, Cork, T12 \\ $\mathrm{R} 5 \mathrm{CP}$, Ireland \\ ${ }^{\mathrm{b}}$ State Key Laboratory of ASIC and System, Shanghai Institute of Intelligent Electronics \& \\ Systems, School of Microelectronics, Fudan University, Shanghai 200433, China \\ ${ }^{\mathrm{c}}$ Nanotechnology and Integrated Bioengineering Centre, Ulster University, Shore Road, Co \\ Antrim, BT37 OQB, Northern Ireland
}

Corresponding author:

"E-mail: Michael.nolan@tyndall.ie. Tel: +353 0212346983 


\begin{abstract}
Ruthenium is a promising material in the semiconductor industry and is investigated as the interconnect metal or as a seed layer for $\mathrm{Cu}$ interconnects. Non-oxidative reactants are required in a plasma-enhanced atomic layer deposition (PE-ALD) process for metals to avoid oxygen contamination. The PE-ALD of Ru has been explored experimentally, but the growth mechanism is not clear. In this paper, the reaction mechanism of the cyclopentadienyl $\left(\mathrm{Cp}, \mathrm{C}_{5} \mathrm{H}_{5}\right)$ precursor $\mathrm{RuCp}_{2}$ and $\mathrm{NH}_{\mathrm{x}}$-terminated $\mathrm{Ru}$ surfaces that result from the plasma cycle is studied in detail by first-principle calculations. The $\mathrm{Cp}$ ligands are eliminated by hydrogen transfer and desorb from metal surface as $\mathrm{CpH}$. The results show that on the $\mathrm{NH}_{\mathrm{x}}$-terminated $\mathrm{Ru}$ surface at typical ALD operating condition (temperature range $550 \mathrm{~K}$ to $650 \mathrm{~K}$ ), the first hydrogen transfer is the ratelimiting step and has high barriers, which are $-1.51 \mathrm{eV}$ for $\mathrm{Ru}(001)$ and $2.01 \mathrm{eV}$ for $\mathrm{Ru}(100)$. Assuming that the initial activation barrier for the first hydrogen transfer can be overcome, the two $\mathrm{Cp}$ ligands will be completely eliminated completely on $\mathrm{Ru}(100)$ surface during the metal precursor pulse, resulting in $\mathrm{Ru}$ atoms on the surface, binding to $\mathrm{N}$ atom. But at most only one $\mathrm{Cp}$ ligand is eliminated on $\mathrm{Ru}(001)$ surface, resulting in an RuCp termination on (001) surface. Investigating the precursor coverage, the final surface coverages of final terminations after the metal precursor pulse are $0.85 \mathrm{RuCp} / \mathrm{nm}^{2}$ on the $\mathrm{NH}_{\mathrm{x}}$-terminated $\mathrm{Ru}(001)$ surface and $2.02 \mathrm{Ru} / \mathrm{nm}^{2}$ on the $\mathrm{NH}_{\mathrm{x}}$-terminated $\mathrm{Ru}(100)$ surface. However, if the first $\mathrm{H}$ transfer barrier cannot be overcome, leaving $\mathrm{RuCp}_{2}$ on $\mathrm{NH}_{\mathrm{x}}$-terminated $\mathrm{Ru}$ surfaces, the maximum coverages of $\mathrm{RuCp}_{2}$ on $\mathrm{Ru}(001)$ and $\mathrm{Ru}(100)$ surfaces are $2.54 \mathrm{RuCp}_{2} / \mathrm{nm}^{2}$ and $2.02 \mathrm{RuCp}_{2} / \mathrm{nm}^{2}$. These structures are vital to model the following N-plasma step.
\end{abstract}

\title{
1. Introduction
}


Ruthenium $(\mathrm{Ru})$ thin film is a widely studied material in the semiconductor industry due to its excellent electrical properties and chemical stability. ${ }^{1}$ As the downsizing of semiconductor devices continues, the widely used copper interconnect is coming up against critical issues including diffusion into the substrate dielectric layer and the difficulty to deposit continuous films in ever reducing via volumes. ${ }^{2}$ Due to its low resistivity and high chemical stability, $\mathrm{Ru}$ is a leading candidates in replacing $\mathrm{Cu}$ for interconnects and has been applied as metallization in interconnects or a seed layer for copper interconnects..$^{3-5}$ In addition, Ru can be applied in other device applications, including the gate metal for semiconductor transistors and the electrode material in dynamic random access memory (DRAM) devices. ${ }^{6}$

For the deposition of metal thin films on the high aspect ratio structures typically present in nanoscale devices, atomic layer deposition (ALD) is the only approach that allows conformal deposition and control of growth at the atomic level. ${ }^{7-8}$ Generally, ALD consists of a self-limiting half cycle for each precursor, where the reactions will in principal finish after all available surface sites are consumed. This drives the self-limiting nature of ALD which enables the high level of growth control.

The study of $\mathrm{Ru}$ ALD has used $\mathrm{Cp}$ based precursors, $\mathrm{RuCp} 2$ or $\mathrm{Ru}(\mathrm{EtCp})_{2}$, and $\mathrm{O}_{2} \cdot{ }^{9-10} \mathrm{O}_{2}$ is consumed with the hydrocarbon ligand of metal precursor. The reported primary by-products are $\mathrm{CO}_{2}$ and $\mathrm{H}_{2} \mathrm{O} .{ }^{11}$ The obtained $\mathrm{Ru}$ films then have oxygen impurities. This approach has been extended to deposit noble metals such as $\mathrm{Pd}$ and $\mathrm{Pt}$ references. The surface metal oxides are unstable and decompose to give metals at elevated temperatures. ${ }^{12}$ For thermal ALD of Ru using dimethylbutadiene-based precursor $\mathrm{Ru}(\mathrm{DMBD})(\mathrm{CO})_{3}$ and non-oxidative reactants hydrazine, the achieved growth rate is $0.42 \AA$ /cycle with an ALD temperature window from $200{ }^{\circ} \mathrm{C}$ to $210{ }^{\circ} \mathrm{C} .{ }^{12}$ 
In addition to thermal ALD, plasma-enhanced ALD (PE-ALD) has been used with ammonia or a mixture of $\mathrm{N}_{2}$ and $\mathrm{H}_{2}$ as the N-plasma source. ${ }^{13-15}$ For the PE-ALD of Ru using $\mathrm{RuCp}_{2}$ and $\mathrm{NH}_{3}$ plasma at a temperature of $300^{\circ} \mathrm{C}$, a growth rate of $1.2 \AA$ cycle has been reported, while a growth rate of $1.8 \AA$ A/cycle was reported using $\mathrm{Ru}(\mathrm{EtCp})_{2}$ at $300{ }^{\circ} \mathrm{C} .{ }^{16}$ Organometallic compounds such as $\beta$-diketonates have also been used as $\mathrm{Ru}$ precursors and the deposited $\mathrm{Ru}$ thin films show higher impurity concentration compared to using metallocenes such as $\mathrm{RuCp}_{2}$ as the $\mathrm{Ru}$ precursor. ${ }^{17}$

Since oxygen can be involved in the deposition process, the quality of deposited $\mathrm{Ru}$ thin film depends strongly on the oxygen dose. ${ }^{18-19}$ Obviously, oxygen can result in interfacial metal oxide formation through the oxide $\mathrm{RuO}_{2}{ }^{18}$ To address this problem, non-oxidative reactants such as $\mathrm{NH}_{3}$ or $\mathrm{H}_{2}$ can be used to promote deposition of metal films. ${ }^{20-23}$

The deposited $\mathrm{Ru}$ thin film is crystalline with hexagonal structure. The orientation is random at low temperature. However, the [001] direction will dominate at elevated temperature or increased plasma power. ${ }^{9,24}$ Deposition of $\mathrm{Ru}$ on substrates including $\mathrm{TaN}, \mathrm{Si}$ and $\mathrm{SiO}_{2}$ with PE-ALD shows no nucleation delay in contrast to thermal Ru ALD. ${ }^{16}$ One possible mechanism in PE-ALD is the production of highly reactive plasma radicals which can easily remove ligands and impurities. However, the detailed mechanism of plasma-enhanced ALD is still not known and requires further study of both the metal and the plasma steps.

Density functional theory (DFT) calculations have been successfully applied to study the ALD of metals and metal oxides. ${ }^{25-28}$ There are some outstanding questions, including how to design new precursors with properties such as good volatility and high reactivity ${ }^{29-30}$ or the reaction mechanism during the metal precursor pulse and plasma pulse. A reaction mechanism using oxidative reactants such as $\mathrm{O}_{3}$ and $\mathrm{H}_{2} \mathrm{O}$ has been elucidated. ${ }^{31-35}$ However, when depositing metals, an O-source can promote oxidation of the metal and cause O-contamination. Non-oxidative 
reactants such as $\mathrm{NH}_{3}$ are used in the in PE-ALD of transition metals. ${ }^{36}$ With this in mind, the key advance of the current paper is to determine the reactions that take place during the metal precursor pulse in $\mathrm{Ru}$ ALD which then serves as a foundation for the ongoing investigation of the atomic level mechanism of the plasma pulse, similar to our earlier work ${ }^{37}$ on Co precursor reactions.

A complete PE-ALD process using N-plasma is as follows. After some cycles, the metal surface after the post-plasma stage is actually an $\mathrm{NH}_{\mathrm{x}}$-terminated metal surface, where $x$ can be 1 or $2, \mathrm{NH}$ or $\mathrm{NH}_{2}$. In the first half-cycle, the metal precursor $\mathrm{RuCp}_{2}$ will react with the $\mathrm{NH}_{\mathrm{x}}$-terminated metal surface. The $\mathrm{Cp}$ ligand is eliminated by hydrogen transfer to form $\mathrm{CpH}$, which desorbs from surface. In the second half-cycle, the plasma generated radicals such as $\mathrm{N}_{\mathrm{x}} \mathrm{H}_{\mathrm{y}}, \mathrm{N}$, or $\mathrm{H}$ will react with the precursor fragment-terminated metal surface and the $\mathrm{Ru}$ atoms are deposited on the surface, which is covered by $\mathrm{NH}_{\mathrm{x}}$ groups at the end of second half cycle. In our recent published work, the nature and stability of $\mathrm{NH}_{\mathrm{x}}$-terminated metal surfaces were determined. ${ }^{38}$ The results showed that at typical ALD operating conditions, a temperature range of $550 \mathrm{~K}$ to $650 \mathrm{~K}$, on the $\mathrm{Ru}(001)$ surface, the most stable termination is $\mathrm{NH}$-termination, while on the $\mathrm{Ru}(100)$ surface, a mixture of $\mathrm{NH}$ and $\mathrm{NH}_{2}$ is the most stable surface termination.

In this paper, we explore the reaction mechanism for the metal precursor pulse on $\mathrm{NH}_{\mathrm{x}}$-terminated $\mathrm{Ru}(001)$ and (100) surfaces by DFT calculations. The metal precursor $\mathrm{RuCp}_{2}$ reacts on these $\mathrm{NH}_{\mathrm{x}^{-}}$ terminated surfaces and the hydrogen transfer step is studied in detail with calculation of hydrogen migration barriers and the formation and elimination of $\mathrm{CpH}$. Furthermore, we investigate the role of precursor coverage, aiming to determine the final precursor coverage and termination on $\mathrm{Ru}$ (001) and (100) surfaces. Assuming that the initial activation barrier for the first hydrogen transfer can be overcome, on the $\mathrm{Ru}(100)$ surface, the metal precursor can undergo two hydrogen transfer steps with elimination of the two $\mathrm{Cp}$ ligands. On the $\mathrm{Ru}(001)$ surface, we predict termination with 
RuCp. The most favourable surface coverages of these precursor terminations are $0.85 \mathrm{RuCp} / \mathrm{nm}^{2}$ on the $\mathrm{NH}_{\mathrm{x}}$-terminated $\mathrm{Ru}(001)$ surface and $2.02 \mathrm{Ru} / \mathrm{nm}^{2}$ on the $\mathrm{NH}_{\mathrm{x}}$-terminated $\mathrm{Ru}(100)$ surface. However, if the process temperature would not permit the first $\mathrm{H}$ transfer barrier to be overcome, thus leaving $\mathrm{RuCp}_{2}$ on the $\mathrm{NH}_{\mathrm{x}}$-terminated $\mathrm{Ru}$ surfaces, the maximum coverages of $\mathrm{RuCp}_{2}$ on $\mathrm{Ru}(001)$ and $\mathrm{Ru}(100)$ surfaces are $2.54 \mathrm{RuCp} 2 / \mathrm{nm}^{2}$ and $2.02 \mathrm{RuCp}_{2} / \mathrm{nm}^{2}$.

\section{Methods and Computational Details}

All the calculations are performed on the basis of spin-polarized DFT with the projector augmented wave (PAW) formalism, as implemented in the Vienna $a b$ initio simulations package (VASP 5.4) code. ${ }^{39}$ The generalized gradient approximation (GGA) with the parameterization of PerdrewBurke-Ernzerhof (PBE) is used for the exchange-correlation functional. ${ }^{40-41}$ The valence electrons are 8 for $\mathrm{Ru}, 5$ for $\mathrm{N}, 4$ for $\mathrm{C}$, and 1 for $\mathrm{H}$. The energy cutoff for the plane wave expansion is set to $400 \mathrm{eV}$. The convergence of energy and forces are set to $1 \times 10^{-4} \mathrm{eV}$ and $0.01 \mathrm{eV} / \square$, respectively. The bulk Ru crystal structure is optimized by simultaneously relaxing the ionic positions, cell volume and cell shape at a higher plane wave energy cutoff of 550eV and a Monkhorst-Pack grid

k-point mesh ${ }^{42}$ of $12 \times 12 \times 6$. The resulting lattice constants are $a=b=2.71 \AA$, and $c=4.28 \AA$ for Ru bulk.

The deposited $\mathrm{Ru}$ films by ALD are polycrystalline and have random surface orientations after low temperature deposition. Based on our previous study ${ }^{38}$ on the stability of $\mathrm{NH} / \mathrm{NH}_{2}$ terminations, we have chosen the most stable (001) surface and the least stable, and high reactivity (100) surface, to investigate the precursor reaction mechanism. The (001) surface has smaller surface area than the (100) surface. Thus, a (4×4) supercell is used to simulate $R u(001)$ surface 
while a $(3 \times 3)$ supercell is used to simulate $\mathrm{Ru}(100)$ surface. The calculated surface areas are $1.18 \mathrm{~nm}^{2}$ for $\mathrm{Ru}(001)$ and $0.99 \mathrm{~nm}^{2}$ for $\mathrm{Ru}(100)$. For (001) surface, a five-layer structure is built with the bottom three-layers fixed during the calculation; while for (100) surface, due to the unique zigzag structure, a four-bilayer (in total eight layers) structure is built with the bottom two-bilayer (bottom four layers) fixed during the calculations. From our previous studies, this is sufficient to model these Ru surfaces. ${ }^{38}$

A k-point mesh ${ }^{42}$ of $2 \times 2 \times 1$ is used in $(4 \times 4)$ supercell and that for the $(3 \times 3)$ supercell is $3 \times 2 \times$ 1. Our previous DFT study ${ }^{38}$ of $\mathrm{NH}_{\mathrm{x}}$ saturation coverage shows that at zero-K condition, where coverage is maximum, the $\mathrm{Ru}(001)$ surface is terminated with $1 \mathrm{ML} \mathrm{NH}$, which is modelled by 16 $\mathrm{NH}$ species in our (4×4) supercell. The termination on $\mathrm{Ru}(100)$ surface is $1 \mathrm{ML} \mathrm{NH}$ and $1 \mathrm{ML} \mathrm{NH}_{2}$ due to the trench structure, which contains $9 \mathrm{NH}$ and $9 \mathrm{NH}_{2}$ in our $(3 \times 3)$ supercell. $\mathrm{NH}$ prefers channel bridge site and $\mathrm{NH}_{2}$ prefers surface bridge site. The configurations of single $\mathrm{NH}$ or $\mathrm{NH}_{2}$ species adsorbed on preferred sites are shown in Figure S1 in supporting information. The saturation coverages are summarized in Table 1 . The configurations of the $\mathrm{NH}_{\mathrm{x}}$-terminated $\mathrm{Ru}$ surfaces at maximum coverage are shown in Figure 1(a)-(b). The side view of these $\mathrm{NH}_{\mathrm{x}^{-}}$ terminated Ru surfaces is shown in Figure S2 of supporting information.

Table 1. The calculated saturation coverages on $\mathrm{Ru}(001)$ and (100) surfaces at zero-K (maximum coverages) and ALD conditions (low coverages).

\begin{tabular}{ccc}
\hline & $\mathrm{Ru}(001)$ & $\mathrm{Ru}(100)$ \\
& $(4 \times 4)$ & $(3 \times 3)$ \\
\hline Zero-K condition & $1 \mathrm{ML} \mathrm{NH}$ & $1 \mathrm{ML} \mathrm{NH}+1 \mathrm{ML} \mathrm{NH}_{2}$ \\
ALD condition & $0.89 \mathrm{ML} \mathrm{NH}$ & $0.67 \mathrm{ML} \mathrm{NH}+0.67 \mathrm{ML} \mathrm{NH}_{2}$ \\
\hline
\end{tabular}


(a)

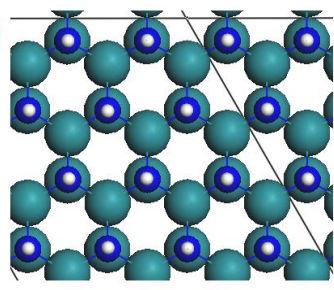

$1 \mathrm{ML}$ NH Ru(001)

(c)

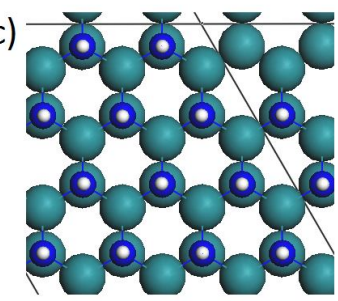

$0.89 \mathrm{MLNH}$ Ru(001) (b)

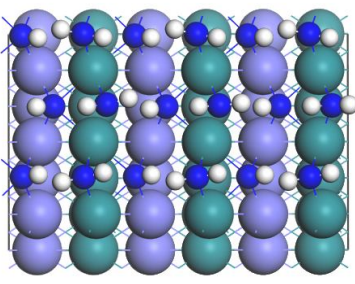

$1 \mathrm{MLNH}+1 \mathrm{ML} \mathrm{NH}$

$\mathrm{Ru}(100)$

(d)

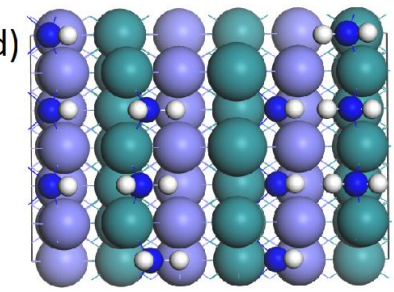

$0.67 \mathrm{ML} \mathrm{NH}+0.67 \mathrm{ML} \mathrm{NH}_{2}$ $\mathrm{Ru}(100)$
zero-K

condition

ALD operating

condition

(550K-650K)

Figure 1. The top view of $\mathrm{NH}_{\mathrm{x}}$-terminated $\mathrm{Ru}$ surface at zero-K or high coverage condition including (a) $\mathrm{Ru}(001)$, and (b) $\mathrm{Ru}(100)$ and at ALD operating condition, with lower coverage including (c) $\mathrm{Ru}(001)$, and (d) $\mathrm{Ru}(100)$. $\mathrm{Ru}$ atoms are represented by green colour for surface terminating atoms and purple colour for the channel atoms in the (100) surface; $\mathrm{N}$ atom and $\mathrm{H}$ atom are represented by dark blue and white atom, respectively.

At the ALD operating condition (temperature range $550 \mathrm{~K}$ to $650 \mathrm{~K}$ ), some of the surface $\mathrm{NH}_{\mathrm{x}}$ species desorb from the surface. The $\mathrm{NH}_{\mathrm{x}}$ saturation coverages are as follows: $\mathrm{Ru}(001)$ surface is terminated with $0.89 \mathrm{ML} \mathrm{NH}$, which is $14 \mathrm{NH}$ in $(4 \times 4)$ supercell and the $\mathrm{Ru}(100)$ surface is terminated with $0.67 \mathrm{ML} \mathrm{NH}$ and $0.67 \mathrm{ML} \mathrm{NH}_{2}$, which contains $6 \mathrm{NH}$ and $6 \mathrm{NH}_{2}$ in $(3 \times 3)$ supercell. The configurations of $\mathrm{NH}_{\mathrm{x}}$-terminated $\mathrm{Ru}$ surfaces at the ALD operating condition are shown in Figure 1(c)-(d). On the (100) surface, due to the trench structure, NH prefers channel bridge site and $\mathrm{NH}_{2}$ prefers surface bridge site.

The molecular geometry of the precursor $\mathrm{RuCp}_{2}$ is relaxed in the same supercell as $\mathrm{Ru}(001)$ with the energy cutoff at $400 \mathrm{eV}$ and Gamma point sampling. The van der Waals correction is applied with PBE-D3 method to ensure an accurate description of the metal precursor adsorption energy. ${ }^{43}$ 
The activation barriers reported in this paper are computed using climbing image nudged elastic band (CI-NEB) method ${ }^{44}$ with 6 images including the starting and ending geometries and with the forces converged to $0.05 \mathrm{eV} / \AA$.

\section{Results and Discussions}

\subsection{Metal precursor adsorption on $\mathrm{NH}_{x}$-terminated $\mathrm{Ru}(001)$ and (100) surfaces}

For free metal precursor $\mathrm{RuCp}_{2}$, the distance between the two $\mathrm{Cp}$ rings is $3.62 \AA$ and the $\mathrm{Ru}-\mathrm{C}$ distance is $2.18 \AA$. When adsorbed on the $\mathrm{NH}_{\mathrm{x}}$-terminated metal surfaces, the metal precursor can be placed perpendicular to substrate with one $\mathrm{Cp}$ ring interacting with the surface (which we term the upright adsorption mode) or parallel to surface with both $\mathrm{Cp}$ rings interacting with the surface (which we term the horizontal adsorption mode). An upright adsorption mode with one ring interacting with the surface and one ring pointing away from the surface has been reported for the adsorption of $\mathrm{FeCp}_{2}$ on silica. ${ }^{45}$ The adsorption energy is calculated from:

$$
E_{a d}=E_{\text {tot }}-E_{\frac{N H x}{\text { Metal }}}-E_{A}
$$

where $\mathrm{E}_{\mathrm{tot}}, \mathrm{E}_{\mathrm{NH} / \mathrm{Metal}}$, and $\mathrm{E}_{A}$ are the energy of the $\mathrm{NH}_{\mathrm{x}}$-terminated metal slab with precursor $\mathrm{RuCp}_{2}$, the slab model for the $\mathrm{NH}_{\mathrm{x}}$-terminated metal surface, and isolated precursor $\mathrm{RuCp}_{2}$, respectively. A negative adsorption energy corresponds to exothermic adsorption. All the energies are computed with the van der Waals correction included. We will use the $\mathrm{NH}_{\mathrm{x}}$ coverages obtained at zero $\mathrm{K}$ and ALD conditions to explore the effect of $\mathrm{NH}_{\mathrm{x}}$ coverage on the $\mathrm{RuCp} 2$ precursor pulse.

The calculated adsorption energies of $\mathrm{RuCp}_{2}$ on $\mathrm{NH}_{\mathrm{x}}$-terminated $\mathrm{Ru}(001)$ and (100) surfaces at maximum $\mathrm{NH}_{\mathrm{x}}$ coverages and low coverages are shown in Table 2. At maximum $\mathrm{NH}_{\mathrm{x}}$ coverages, 
$\mathrm{Ru}(001)$ is terminated with $1 \mathrm{ML} \mathrm{NH}$ and $\mathrm{Ru}(100)$ has a mixed termination with $1 \mathrm{ML}$ NH and $1 \mathrm{ML} \mathrm{NH}$. On $\mathrm{Ru}(001)$ surface, the metal precursor prefers to bind to the substrate through only one $\mathrm{Cp}$ ring and the precursor is in the upright position; while on $\mathrm{Ru}(100)$ surface, the metal precursor prefers to bind to the substrate through both $\mathrm{Cp}$ rings and the precursor is in the horizontal configuration. These structures are shown in Figure 2(a)-(b).

At low $\mathrm{NH}_{\mathrm{x}}$ coverage, the binding preference of the metal precursor at both surfaces is unchanged from the maximum $\mathrm{NH}_{\mathrm{x}}$ coverages and these structures are shown in Figure 2(c)-(d). At low coverage, after adsorption on $\mathrm{Ru}(100)$ surface, one channel $\mathrm{NH}$ migrates to surface site. The configurations of less stable adsorption structures are shows in Figure S3.

(a)
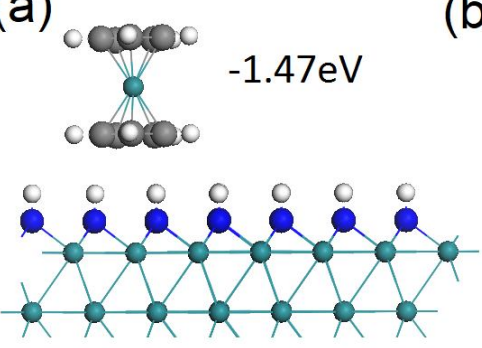

(c)
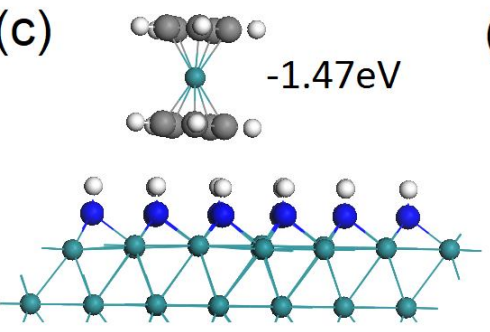

(b)
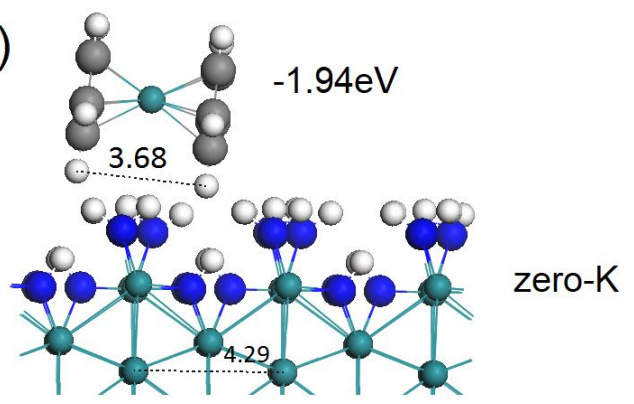

(d)

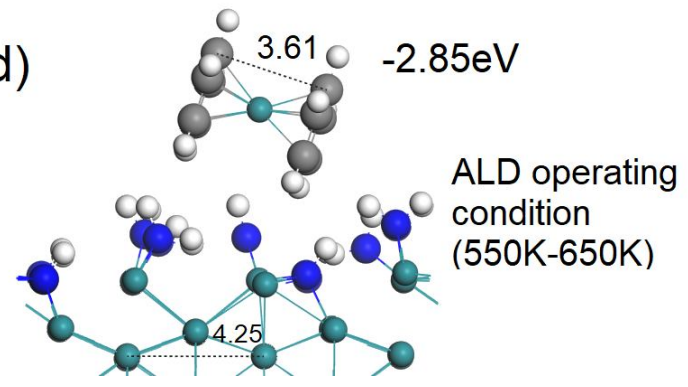

Figure 2. The configurations of the most stable adsorption mode of precursor $\mathrm{RuCp}_{2}$ on (a) $\mathrm{Ru}(001)$ surface, and (b) $\mathrm{Ru}(100)$ surface at zero-K and on (c) $\mathrm{Ru}(001)$ surface, and (d) $\mathrm{Ru}(100)$ surface at ALD operating condition. $\mathrm{Ru}$ atoms are represented by green colour. $\mathrm{N}$ atom and $\mathrm{H}$ atom are represented by dark blue and white atom, respectively. 
Table 2. The calculated adsorption energy of metal precursor $\mathrm{RuCp}_{2}$ adsorbed on $\mathrm{NH}_{\mathrm{x}}$-terminated $\mathrm{Ru}(001)$ and (100) surfaces. The $\mathrm{NH} / \mathrm{NH}_{2}$ terminations include the maximum $\mathrm{NH}_{\mathrm{x}}$ coverages at zero-K and low coverages at ALD operating condition (temperature range $550 \mathrm{~K}-650 \mathrm{~K}$ ).

\begin{tabular}{ccc|cc}
\hline & \multicolumn{2}{c|}{ Maximum coverages } & \multicolumn{2}{c}{ Low coverages } \\
\hline & $\mathrm{Ru}(001)$ & $\mathrm{Ru}(100)$ & $\mathrm{Ru}(001)$ & $\mathrm{Ru}(100)$ \\
\hline upright & -1.47 & -0.77 & -1.47 & -0.57 \\
horizontal & -1.28 & -1.94 & -0.61 & -2.85 \\
\hline
\end{tabular}

This difference in binding mode is due to the different surface structures. $\mathrm{Ru}(001)$ surface has a flat surface structure, while $\mathrm{Ru}(100)$ surface has a unique zigzag structure. On the $\mathrm{Ru}(001)$ surface, an upright position with one $\mathrm{Cp}$ ring close to metal surface can result in stronger adsorption strength. With this upright binding mode, each carbon atom in the $\mathrm{Cp}$ ring closest to the surface is potentially available for the hydrogen transfer step to form $\mathrm{CpH}$.

At maximum coverages, the distances between the two Cp rings are in the range of $3.59 \AA$ to $3.63 \AA$ for $\mathrm{RuCp}_{2}$ on $\mathrm{Ru}(001)$ surface. The distances for metal-C are in the range of $2.17 \AA$ and $2.19 \AA$. Compared to free $\mathrm{RuCp}_{2}$, the two $\mathrm{Cp}$ rings are slightly tilted. On $\mathrm{Ru}(100)$ surface, the distance across the trench (between two neighbouring metal atoms) is $4.29 \AA$. The distances between the two $\mathrm{Cp}$ rings in precursors are in the range of $3.56 \AA$ to $3.68 \AA$ for $\mathrm{RuCp} 2$ on $\mathrm{Ru}(100)$ surface. The two $\mathrm{Cp}$ rings are obviously tilted compared to adsorbed $\mathrm{RuCp} \mathrm{p}_{2}$ on $\mathrm{Ru}(001)$ surface and free $\mathrm{RuCp} \mathrm{p}_{2}$. The metal precursor can be well-accommodated within the trench of (100) surface, which can result in stronger adsorption strength. 
At low coverages, the distances between the two Cp rings are in the range of $3.59 \AA$ to $3.64 \AA$ for $\mathrm{RuCp}_{2}$ on $\mathrm{Ru}(001)$ surface. The distances for metal-C are between $2.17 \AA$ and $2.20 \AA$. The $\mathrm{NH}_{\mathrm{x}}$ coverages have little effect on the adsorption of $\mathrm{RuCp}_{2}$ on (001) surface, for which the adsorption energy is $-1.47 \mathrm{eV}$. On the $\mathrm{Ru}(100)$ surface, the distance of the trench (two neighbouring metal atoms) is $4.25 \AA$. The distances between the two $\mathrm{Cp}$ rings are in the range of $3.61 \AA$ to $3.65 \AA$ for

$\mathrm{RuCp}_{2}$ on $\mathrm{Ru}(100)$ surface. The distances for metal-C are between $2.18 \AA$ and $2.19 \AA$. The adsorbed $\mathrm{RuCp}_{2}$ on $\mathrm{NH}_{\mathrm{x}}$ terminations at low coverages is less tilted compared to the maximum $\mathrm{NH}_{\mathrm{x}}$ coverage. With this flat binding mode, the carbon atoms closest to the surface are available for hydrogen transfer to form $\mathrm{CpH}$. We found a similar stability for $\mathrm{CoCp}_{2}$ on $\mathrm{NH}_{\mathrm{x}}$-terminated Co (001) and (100) surfaces in earlier work ${ }^{37}$, which suggests that the geometry of the surface plays a key role in the initial adsorption of the metal precursor.

\subsection{Single precursor reaction pathway on $\mathrm{Ru}(001)$ and (100) surfaces with $\mathrm{NH}_{x}$ terminations at}

\section{ALD operating condition}

The reaction pathway during the metal precursor pulse is studied with respect to the $\mathrm{NH}_{\mathrm{x}}$ terminations at ALD operating condition. In this section, we address the reaction mechanism when single $\mathrm{RuCp} 2$ precursor is adsorbed on $\mathrm{NH}_{\mathrm{x}}$-terminated $\mathrm{Ru}(001)$ and (100) surfaces. Once the metal precursor is adsorbed on these $\mathrm{NH}_{\mathrm{x}}$-terminated metal surfaces, the $\mathrm{Cp}$ ligand can undergo hydrogen transfer, $\mathrm{CpH}$ formation, $\mathrm{CpH}$ desorption, second hydrogen transfer, and second $\mathrm{CpH}$ formation and desorption.

Upon adsorption, no spontaneous hydrogen transfer was observed on any $\mathrm{NH}_{\mathrm{x}}$-terminated $\mathrm{Ru}$ (001) and (100) surfaces. This means that the hydrogen transfer step must overcome an activation 
barrier. The possible reactions of single adsorbed molecule of $\mathrm{RuCp}_{2}$ on $\mathrm{NH}_{\mathrm{x}}$-terminated metal surfaces can be illustrated as follows:

$$
\begin{gathered}
A: H^{*}+R u C p_{2} \rightarrow R u C p^{*}+H C p \\
B: H^{*}+R u C p \rightarrow R u^{*}+H C p
\end{gathered}
$$

where reaction $\mathrm{A}$ involves the first $\mathrm{Cp}$ ligand and reaction $\mathrm{B}$ involves the second $\mathrm{Cp}$ ligand. We have calculated the energy along the reaction pathway and the activation barriers for hydrogen transfer at each step. The reaction energies of precursor adsorption ( $\left.\mathrm{E}_{\text {adsorption }}\right)$, hydrogen transfer $\left(\mathrm{E}_{\text {hydrogen }} \mathrm{I} / \mathrm{E}_{\text {hydrogen }}{ }^{\mathrm{II}}\right)$ and $\mathrm{CpH}$ desorption $\left(\mathrm{E}^{\mathrm{Des}} \mathrm{CpH}^{\mathrm{I}}, \mathrm{E}^{\mathrm{Des}} \mathrm{CpH}^{\mathrm{II}}\right)$ are with reference to the $\mathrm{NH}_{\mathrm{x}^{-}}$ terminated metal surface and free $\mathrm{RuCp}_{2}$ as reactants and free $\mathrm{CpH}$ as a product.

The results for $\mathrm{NH}_{\mathrm{x}}$ terminations at ALD operating condition are summarized in Figure 3 and the calculated barriers for the hydrogen transfer steps are presented in Table 3 . In order to assess any role of $\mathrm{NH} / \mathrm{NH}_{2}$ coverage, the results for $\mathrm{NH}_{\mathrm{x}}$ terminations at highest coverage, i.e. zero $\mathrm{K}$, are summarized in Figure S4 and the calculated barrier for the hydrogen transfer steps are presented in Table S1 in supporting information.

Table 3. The calculated reaction energy for hydrogen transfer step and reaction barriers on $\mathrm{Ru}$ (001) and (100) surfaces with $\mathrm{NH}_{\mathrm{x}}$ terminations corresponding to ALD operating condition. If the reaction energies of hydrogen transfer step are positive, the barriers are not calculated.

\begin{tabular}{cccc|ccc}
\hline & $A: H^{*}+R u C p_{2} \rightarrow R u C p^{*}+H C p$ & \multicolumn{3}{|c}{$B: H^{*}+R u C p \rightarrow R u^{*}+H C p$} \\
\hline & Eadsorption & Ehydrogen $^{\text {I }}$ & $\mathrm{E}_{\text {barrier }}$ & $\mathrm{E}^{\text {Des }}{ }_{\mathrm{CpH}}{ }^{\mathrm{I}}$ & E $_{\text {hydrogen }}{ }_{\text {II }}$ & $\mathrm{E}_{\text {barrier }}$ \\
\hline $\mathrm{Ru}(001)$ & -1.47 & 0.03 & 1.51 & 0.71 & 1.44 & Not Calculated \\
$\operatorname{Ru}(100)$ & -2.85 & -1.44 & 2.01 & -2.14 & -1.68 & 1.00 \\
\hline
\end{tabular}



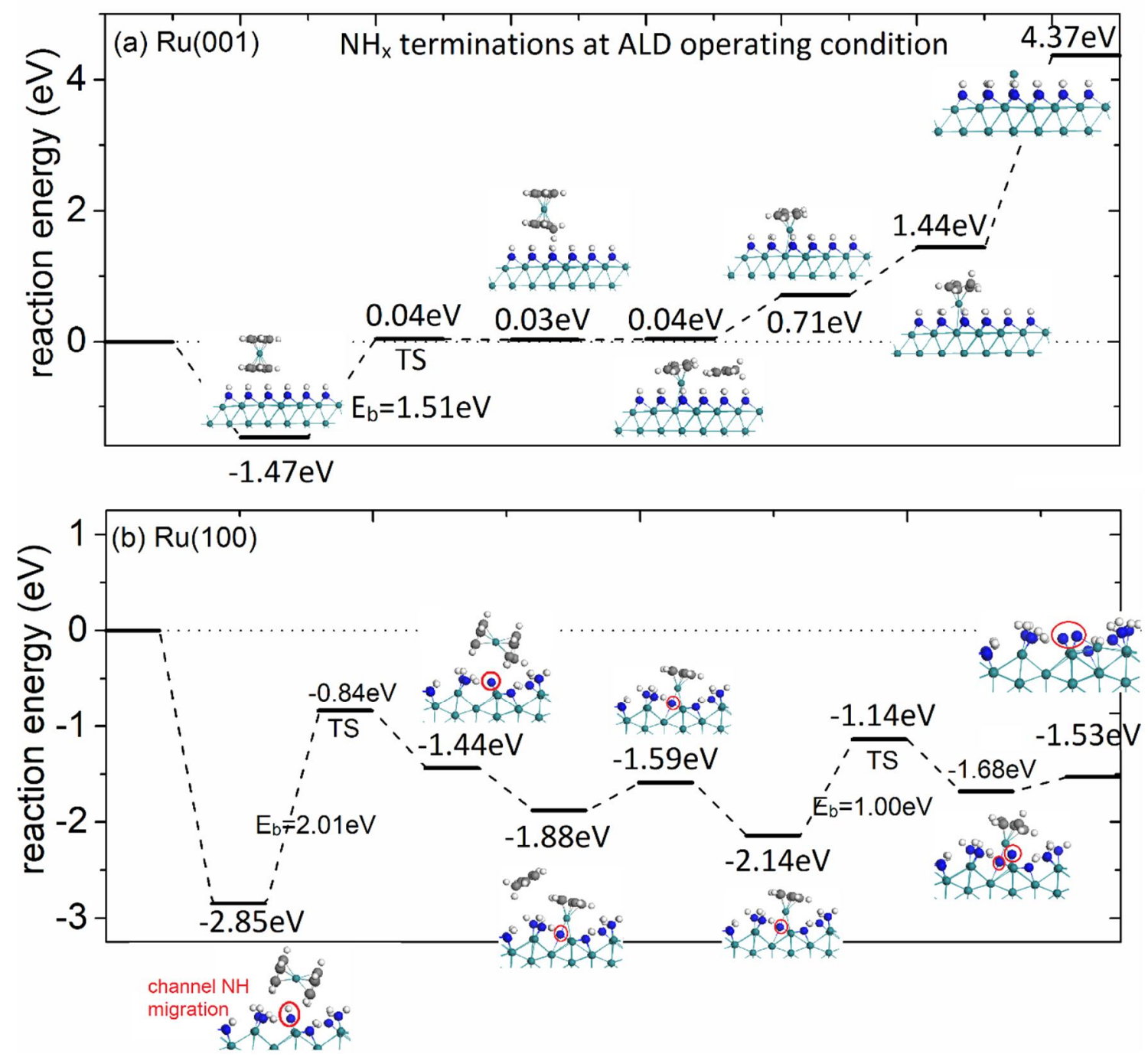

Figure 3. The plotted metal precursor reaction pathway on (a) $\mathrm{Ru}(001)$ surface and (b) $\mathrm{Ru}(100)$ surface with $\mathrm{NH}_{\mathrm{x}}$ terminations at ALD operating condition. The $\mathrm{Cp}$ ligand is eliminated via hydrogen transfer. The substrate $\mathrm{Ru}$ atoms are represented by green spheres. Carbon, nitrogen and hydrogen atoms are represented by grey, blue and white colour, respectively. The red ring for $\mathrm{Ru}$ (100) highlights ....

At the $\mathrm{Ru}(001)$ surface, $\mathrm{RuCp}_{2}$ has a strong adsorption strength with a negative adsorption energy of $-1.47 \mathrm{eV}$. The first hydrogen transfer step has a barrier of $1.51 \mathrm{eV}$, while the first $\mathrm{CpH}$ desorption, to yield the RuCp surface termination, is endothermic by $0.71 \mathrm{eV}$. Computing the energy for the 
second $\mathrm{CpH}$ formation and desorption, we see that the reaction energy is as high as $4.37 \mathrm{eV}$. Therefore, the final surface termination after introduction of single $\mathrm{RuCp}_{2}$ precursor is possibly RuCp-terminated, assuming that the initial activation barrier for the first hydrogen transfer can be overcome.

At the highest $\mathrm{NH}_{\mathrm{x}}$ coverage, the termination on $\mathrm{Ru}(001)$ is $1 \mathrm{ML} \mathrm{NH}$. As shown on Figure $\mathrm{S} 4(\mathrm{a})$, the first hydrogen transfer has a barrier of $1.33 \mathrm{eV}$. With the presence of adsorbed $\mathrm{CpH}$, the second hydrogen transfer has a moderate barrier of $0.98 \mathrm{eV}$. However, the energy cost of the desorption of the second $\mathrm{CpH}$ is as high as $2.92 \mathrm{eV}$. This suggests a $\mathrm{RuCp}$ termination on the (001) facet irrespective of the $\mathrm{NH}_{\mathrm{x}}$ coverage.

On the $\mathrm{Ru}(100)$ surface, we find that for the hydrogen transfer step, channel $\mathrm{H}$ atom is more reactive than surface $\mathrm{H}$ atom. As listed in Table 4, if the hydrogen transfer is from $\mathrm{H}$ atom of surface $\mathrm{NH}_{2}$, after structure relaxing, surface $\mathrm{N}$ will grab the $\mathrm{H}$ atom from channel $\mathrm{NH}$ and revert to surface $\mathrm{NH}_{2}$. Thus, in the discussion on $\mathrm{Ru}(100)$ surface, the channel $\mathrm{H}$ atom contributes to the hydrogen transfer. In addition, as shown in Figure 3(b), we found that for each hydrogen transfer step, the channel $\mathrm{H}$ migrates to a surface site and contributes to the hydrogen transfer.

$\mathrm{On} \mathrm{Ru}(100)$ surface at $\mathrm{ALD}$ conditions, the favourable $\mathrm{NH}_{\mathrm{x}}$-termination is $6 \mathrm{NH}$ and $6 \mathrm{NH}_{2}$. The overall reaction of $\mathrm{Cp}$ ligand elimination via hydrogen transfer is exothermic. Upon adsorption, $\mathrm{RuCp}_{2}$ has a high exothermic adsorption energy of $-2.85 \mathrm{eV}$. Due to the strong adsorption strength, the resulting first hydrogen transfer step has a high computed activation barrier of $2.01 \mathrm{eV}$. 
Table 4. The calculated reaction energy for hydrogen transfer step from surface $H$ and channel $\mathrm{H}$ on $\mathrm{Ru}(100)$ surface. The results show that channel $\mathrm{H}$ is more reactive than surface $\mathrm{H}$ on $\mathrm{Ru}(100)$ surface.

\begin{tabular}{ccc}
\hline & Zero-K condition & ALD condition \\
\hline Ru(100)/eV & $\mathrm{Ru}(100) / \mathrm{eV}$ \\
adsorption & -1.94 & -2.85 \\
$\begin{array}{c}\text { hydrogen transfer } \\
\text { channel H }\end{array}$ & -0.79 & -1.44 \\
$\begin{array}{c}\text { hydrogen transfer } \\
\text { surface } \mathrm{H}\end{array}$ & -0.05 & revert to $\mathrm{NH}_{2}$ \\
\hline
\end{tabular}

After the first $\mathrm{Cp}$ ligand desorption, another channel $\mathrm{NH}$ migrates to surface site, ready to react with the second $\mathrm{Cp}$ ligand. The second hydrogen transfer reaction has a lower barrier of $1.00 \mathrm{eV}$. Finally, after the second $\mathrm{Cp}$ ligand desorption, the energy gain is $-1.53 \mathrm{eV}$. This implies that upon adsorption of $\mathrm{RuCp}_{2}$ on $\mathrm{Ru}(100)$ at $0.67 \mathrm{ML} \mathrm{NH}$ and $0.67 \mathrm{ML} \mathrm{NH}_{2}$ terminations, two hydrogen transfer steps can take place, although whether this is possible is determined the process temperature, given the magnitude of the barrier for the first hydrogen transfer as a result of the extremely stable adsorption mode of the $\mathrm{RuCp}_{2}$ precursor.

At the highest $\mathrm{NH}_{\mathrm{x}}$ coverage, the termination on $\mathrm{Ru}(100)$ is $1 \mathrm{ML} \mathrm{NH}+1 \mathrm{ML} \mathrm{NH}$. As shown on Figure $\mathrm{S} 4(\mathrm{~b})$, the first hydrogen transfer has a high barrier of $2.72 \mathrm{eV}$. At this maximum coverage, there are no available surface or channel sites. Thus, the migration of channel NH to surface site is not found. After the desorption of $\mathrm{CpH}$, the second hydrogen transfer is not favoured due to positive reaction energy. This suggests a $\mathrm{RuCp}_{2} \mathrm{H}$ termination at maximum $\mathrm{NH}_{\mathrm{x}}$ coverage, which 
shows that the $\mathrm{NH}_{\mathrm{x}}$ terminations can play a role in the activation barrier and reaction energy for Cp ligand elimination via hydrogen transfer.

In summary, for single metal precursor $\mathrm{RuCp}_{2}$ on $\mathrm{NH}_{\mathrm{x}}$-terminated $\mathrm{Ru}(001)$ and (100) surface at ALD operating condition, the first hydrogen transfer is the rate-limiting step and the computed barriers are high for $\mathrm{Ru}(001)$ and (100) surface, which are $1.51 \mathrm{eV}$ for $\mathrm{Ru}(001)$ and 2.01 for $\mathrm{Ru}(100)$. Assuming that the initial activation barrier for the first hydrogen transfer can be overcome, on the $\mathrm{Ru}(001)$ surface, the second hydrogen transfer is not favoured due to positive reaction energy and endothermic reaction. The termination for a single $\mathrm{RuCp}_{2}$ precursor on $\mathrm{Ru}(001)$ surface is $\mathrm{RuCp}$ fragment on the surface, binding to $\mathrm{N}$ atom. The distance between the $\mathrm{Ru}$ atom from RuCp fragment and nearest $\mathrm{N}$ atom is $1.88 \square$.

On the $\mathrm{Ru}(100)$ surface, the barriers for the first and second hydrogen transfers are $2.01 \mathrm{eV}$ and $1.00 \mathrm{eV}$. After the desorption of two $\mathrm{CpH}$, the $\mathrm{Ru}$ atom is deposited on the surface with a negative energy gain of $-1.53 \mathrm{eV}$. The termination of single $\mathrm{RuCp} 2$ precursor on $\mathrm{Ru}(100)$ surface is $\mathrm{Ru}$ atom, binding to $\mathrm{N}$ atom. The distance between the deposited $\mathrm{Ru}$ atom and nearest $\mathrm{N}$ atom is $1.89 \square$. These structures are shown in Figure 4.
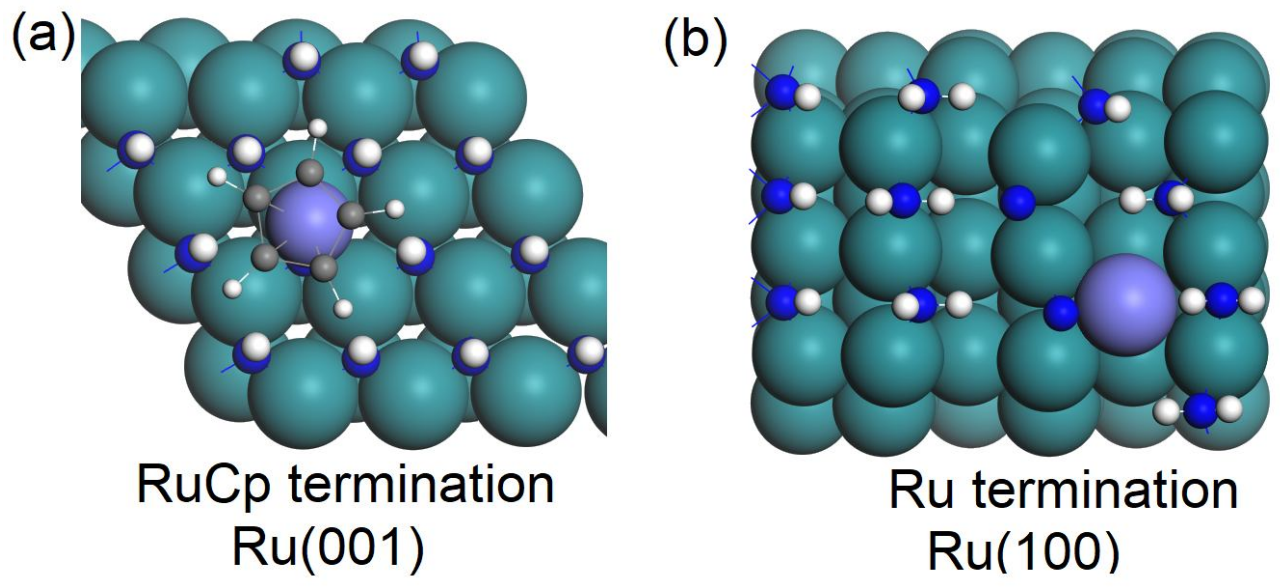
Figure 4. The structures of surface terminations for single $\mathrm{RuCp} 2$ reaction on $\mathrm{NH}_{\mathrm{x}}$-terminated (a) $\mathrm{Ru}(001)$ surface and (b) $\mathrm{Ru}(100)$ surface. The substrate $\mathrm{Ru}$ atoms are represented by green spheres and $\mathrm{Ru}$ atoms from metal precursor are represented by purple spheres. Carbon, nitrogen and hydrogen atoms are represented by grey, blue and white colour, respectively.

\subsection{Precursor coverage effect on the reaction mechanism on $R u(001)$ and (100) surfaces}

with $\mathrm{NH}_{x}$ terminations at ALD operating condition

We now address the adsorption and further reaction of two $\mathrm{Ru}(\mathrm{Cp})_{2}$ precursors. The adsorption energy is calculated from:

$$
E_{a d}=E_{t o t}-E_{\frac{N H x}{\text { Metal }}}-2 * E_{A}
$$

where $\mathrm{E}_{\mathrm{tot}}, \mathrm{E}_{\mathrm{NH} / \mathrm{Metal}}$, and $\mathrm{E}_{A}$ are the energy of the $\mathrm{NH}_{\mathrm{x}}$-terminated metal slab with two $\mathrm{Ru}(\mathrm{Cp})_{2}$ precursors, the slab model for the $\mathrm{NH}_{\mathrm{x}}$-terminated metal surface, and free precursor $\mathrm{RuCp}_{2}$, respectively. Dividing the computed energy by two gives the adsorption energy per precursor. All energies are computed with the inclusion of the van der Waals corrections. The adsorption structures of two precursors on $\mathrm{Ru}(001)$ and (100) surfaces at the ALD coverage of $\mathrm{NH}_{\mathrm{x}}$ are shown in Figure 5.

(a)
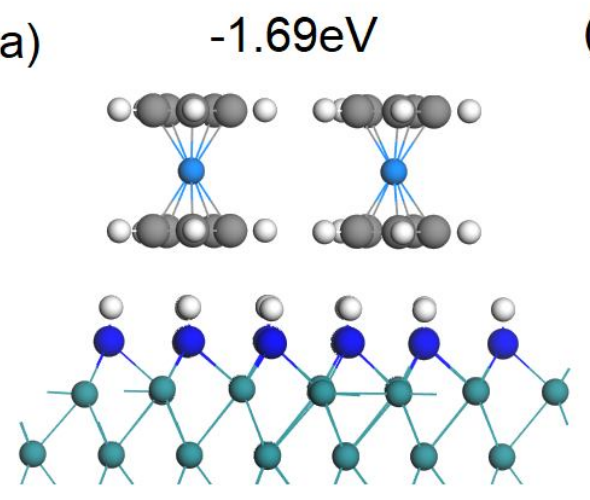

$\mathrm{Ru}(001)$ (b)

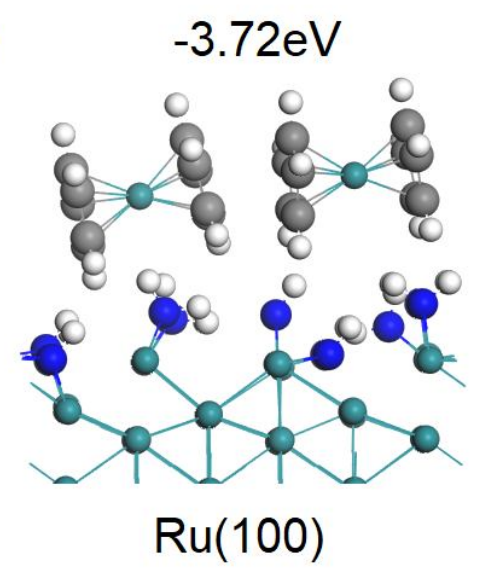


Figure 5. The configurations of two precursor $\mathrm{Rup}_{2}$ on $\mathrm{NH}_{\mathrm{x}}$-terminated (a) $\mathrm{Ru}(001)$ surface, and (b) $\mathrm{Ru}(100)$. The substrate $\mathrm{Ru}$ atoms are represented by green spheres. $\mathrm{Ru}$ atoms from metal precursor $\mathrm{RuCp}_{2}$ are presented by light blue spheres. Carbon, nitrogen and hydrogen atoms are represented by grey, blue and white colour, respectively.

The preferred binding mode for two precursors is the same as for adsorption of single precursor. On the $\mathrm{Ru}(001)$ surface, the upright adsorption mode is the most stable, while on the (100) surface the horizontal adsorption mode is the most stable. These energies of these adsorption modes are exothermic with computed adsorption energies of $-1.69 \mathrm{eV}$ on the $\mathrm{Ru}(001)$ surface and $-3.72 \mathrm{eV}$ on the $\mathrm{Ru}(100)$ surface, resulting in adsorption energies per precursor of $-0.84 \mathrm{eV}$ on $\mathrm{Ru}(001)$ surface and $-1.86 \mathrm{eV}$ on $\mathrm{Ru}(100)$ surface. Thus on both $\mathrm{Ru}(001)$ and (100) surfaces, while precursor adsorption is weaker compared with adsorption of single precursor $(-1.47 \mathrm{eV}$ for $\mathrm{Ru}(001)$ and $2.85 \mathrm{eV}$ for $\mathrm{Ru}(100)$ ), it is still exothermic and there is presumably some precursor-precursor interaction at this coverage in our surface supercell. Additionally, on the $\mathrm{Ru}(100)$ surface, after adsorption, one channel $\mathrm{NH}$ migrates to surface site, similar to our finding for single $\mathrm{RuCp}_{2}$ adsorption on $\mathrm{Ru}(100)$ surface.

The further reaction of two precursor molecules of $\mathrm{RuCp}_{2}$ on the $\mathrm{NH}_{\mathrm{x}}$-terminated metal surfaces at ALD operating condition can proceed as follows:

$$
\begin{gathered}
C: H^{*}+R u C p_{2}+R u C p_{2} \rightarrow R u C p_{2}+R u C p^{*}+H C p \\
D 1: H^{*}+R u C p_{2}+R u C p^{*} \rightarrow R u C p_{2}+R u^{*}+H C p \\
D 2: H^{*}+R u C p_{2}+R u C p^{*} \rightarrow R u C p^{*}+R u C p^{*}+H C p
\end{gathered}
$$

Here, after the first hydrogen transfer, Reaction $\mathrm{C}$, the second hydrogen transfer can result in two different by-products. Reaction $\mathrm{D} 1$ results in an $\mathrm{Ru}$ atom and an intact adsorbed $\mathrm{RuCp} 2$, while in reaction $\mathrm{D} 2$, two adsorbed $\mathrm{RuCp}$ fragments are present on the surface. The reaction energies of 
two precursor adsorption are with reference to the $\mathrm{NH}_{\mathrm{x}}$-terminated metal surface and two free $\mathrm{RuCp}_{2}$. If one $\mathrm{CpH}$ molecule desorbs from the surface, the reaction energies are with reference to $\mathrm{NH}_{\mathrm{x}}$-terminated metal surface, two free $\mathrm{RuCp}_{2}$, and free $\mathrm{CpH}$. The reaction pathways are shown in Figure 6, with Reactions D1 and D2 shown in different colours and the calculated barriers for each hydrogen transfer step are presented in Table 5. 


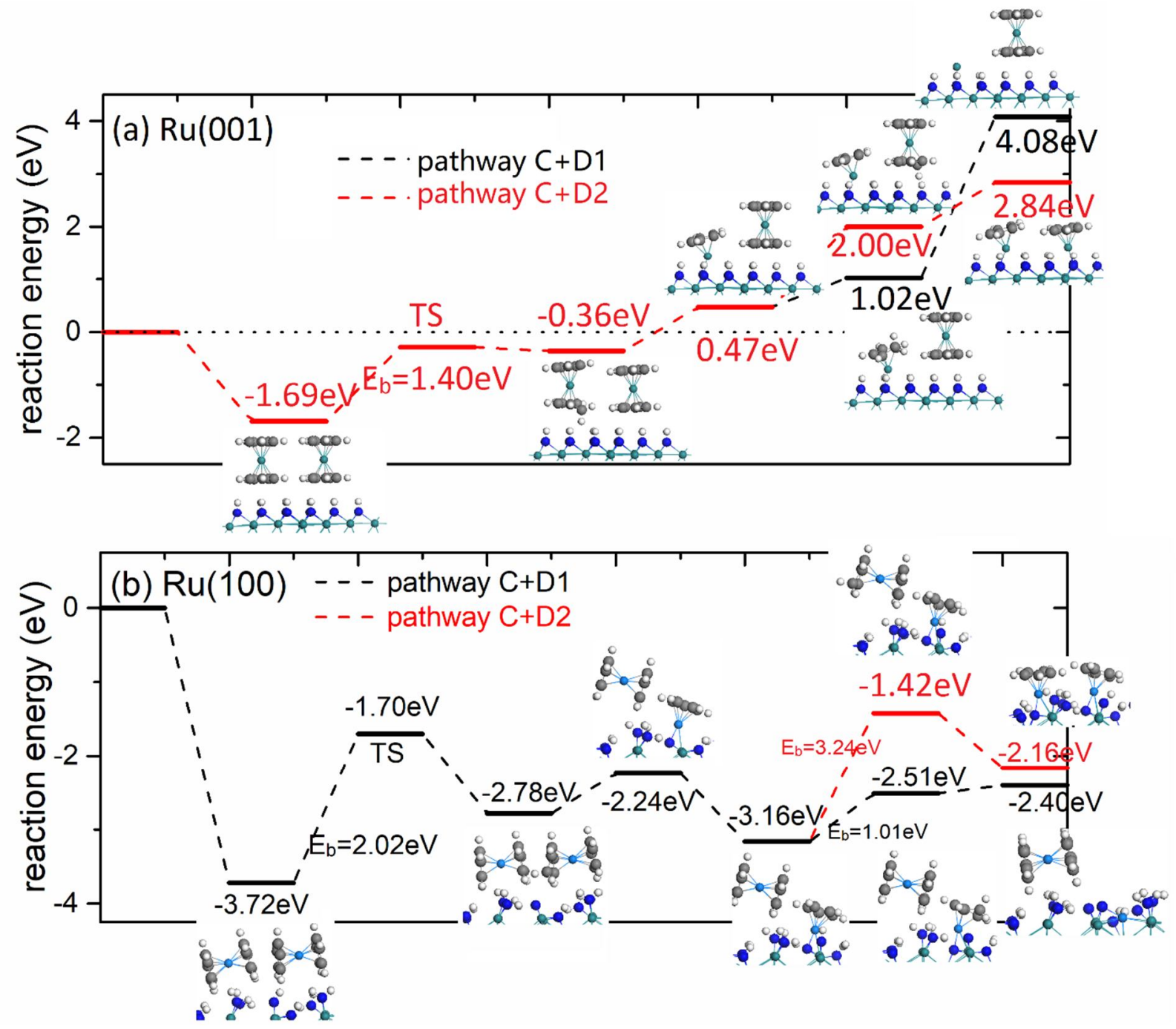

Figure 6. The $\mathrm{RuCp}_{2}$ precursor reaction pathway on (a) $\mathrm{Ru}(001)$ surface and (b) $\mathrm{Ru}(100)$ surface for two $\mathrm{RuCp}_{2}$ precursors. The black pathway is for reaction D1, resulting in a $\mathrm{Ru}$ atom and adsorbed $\mathrm{RuCp}_{2}$. The red pathway is for reaction $\mathrm{D} 2$, resulting in two RuCp fragments at the surface. The $\mathrm{Ru}$ atoms are represented by green spheres. Carbon, nitrogen and hydrogen atoms are represented by grey, blue and white colour, respectively. 
Table 5. The computed energy barriers for hydrogen transfer steps with respect to two metal precursors $\mathrm{RuCp}_{2}$ adsorption on $\mathrm{NH}_{\mathrm{x}}$ terminated $\mathrm{Ru}(001)$ and (100) surfaces at ALD conditions.

\section{Computed Barriers/eV}

\begin{tabular}{lccc}
\hline & $C: H^{*}+R u C p_{2}+R u C p_{2} \rightarrow$ & $D 1: H^{*}+R u C p_{2}+R u C p^{*} \rightarrow$ & $D 2: H^{*}+R u C p_{2}+R u C p^{*} \rightarrow$ \\
& $R u C p_{2}+R u C p^{*}+H C p$ & $R u C p_{2}+R u^{*}+H C p$ & $R u C p^{*}+R u C p^{*}+H C p$ \\
\hline $\operatorname{Ru}(001)$ & 1.40 & Not calculated & Not calculated \\
$\mathrm{Ru}(100)$ & 2.02 & 1.01 & 3.24 \\
\hline
\end{tabular}

On $\mathrm{Ru}(001)$ surface, two $\mathrm{Ru}(\mathrm{Cp})_{2}$ have a moderate adsorption energy of $-1.69 \mathrm{eV}$. The first hydrogen transfer step has a barrier of $1.40 \mathrm{eV}$. Compared with single $\mathrm{RuCp}_{2}$, this barrier is slightly reduced from $1.51 \mathrm{eV}$. After $\mathrm{CpH}$ formation and desorption, the resulting adsorbed $\mathrm{RuCp}$ fragment and $\mathrm{RuCp}_{2}$ has a positive reaction energy at the value of $0.47 \mathrm{eV}$. The second hydrogen transfer via either pathway D1 or pathway D2 is not favoured. This implies that the surface coverage of $\mathrm{RuCp}_{2}$ has little effect on $\mathrm{Cp}$ ligand elimination. With two $\mathrm{RuCp}_{2}$ on $\mathrm{Ru}(001)$ surface, at most only one Cp ligand is eliminated.

On $\mathrm{Ru}(100)$ surface, the overall reaction of $\mathrm{Cp}$ ligand elimination via hydrogen transfer is exothermic. After adsorption of two $\mathrm{RuCp}_{2}$, the channel $\mathrm{NH}$ migrates to surface site, resulting in strong adsorption energy of $-3.72 \mathrm{eV}$. The migration of channel NH to surface site is also observed for single $\mathrm{RuCp}_{2}$ adsorption and $\mathrm{Cp}$ ligand elimination via hydrogen transfer. Due to this strong adsorption, the first hydrogen transfer has a high barrier at the value of $2.02 \mathrm{eV}$. Compared with single $\mathrm{RuCp}_{2}$, there is no difference in the barrier values. After the first $\mathrm{CpH}$ formation and desorption, another channel NH migrates to surface NH. For the second hydrogen transfer, 
pathway $\mathrm{D} 1$ results in a $\mathrm{Ru}$ atom and $\mathrm{RuCp}_{2}$ on the surface, and pathway $\mathrm{D} 2$ results in two $\mathrm{RuCp}$ fragments. The barrier analysis indicates that pathway D1 has a moderate barrier at the value of $1.01 \mathrm{eV}$, but pathway $\mathrm{D}_{2}$ has a high barrier of $3.24 \mathrm{eV}$. Thus, on $\mathrm{Ru}(100)$ surface with two $\mathrm{RuCp} 2$, the preferred surface termination is a deposited $\mathrm{Ru}$ atom binding to $\mathrm{N}$ atom and adsorbed $\mathrm{RuCp} 2$.

On $\mathrm{Ru}(100)$ surface, after the elimination of two $\mathrm{Cp}$ ligands from the first $\mathrm{RuCp}_{2}$ precursor, we then further investigate hydrogen transfer and $\mathrm{Cp}$ elimination for the second $\mathrm{RuCp} 2$ precursor, with the deposited $\mathrm{Ru}$ on the $\mathrm{Ru}(100)$ surface. The reactions are illustrated as follows:

$$
\begin{gathered}
E: H^{*}+R u C p_{2}+R u^{*} \rightarrow R u C p^{*}+R u^{*}+H C p \\
F: H^{*}+R u C p^{*}+R u^{*} \rightarrow R u^{*}+R u^{*}+H C p
\end{gathered}
$$

The results are summarized in Figure 7. Before the first hydrogen transfer, there is surface rearrangement via $\mathrm{H}_{2}$ formation from one surface $\mathrm{H}$ and one channel $\mathrm{H}$, which has an energy gain of $-0.35 \mathrm{eV}$. This is important for the elimination of surface $\mathrm{NH}_{\mathrm{x}}$ species during the growth process. The first hydrogen transfer has a barrier of $1.67 \mathrm{eV}$. After the first $\mathrm{CpH}$ formation and desorption, the second hydrogen transfer has a moderate barrier of $1.30 \mathrm{eV}$. After the second $\mathrm{CpH}$ desorption, two $\mathrm{Ru}$ atoms are deposited on the surface, binding to $\mathrm{N}$ atom. The energy cost for the second $\mathrm{CpH}$ desorption is $1.62 \mathrm{eV}$. 


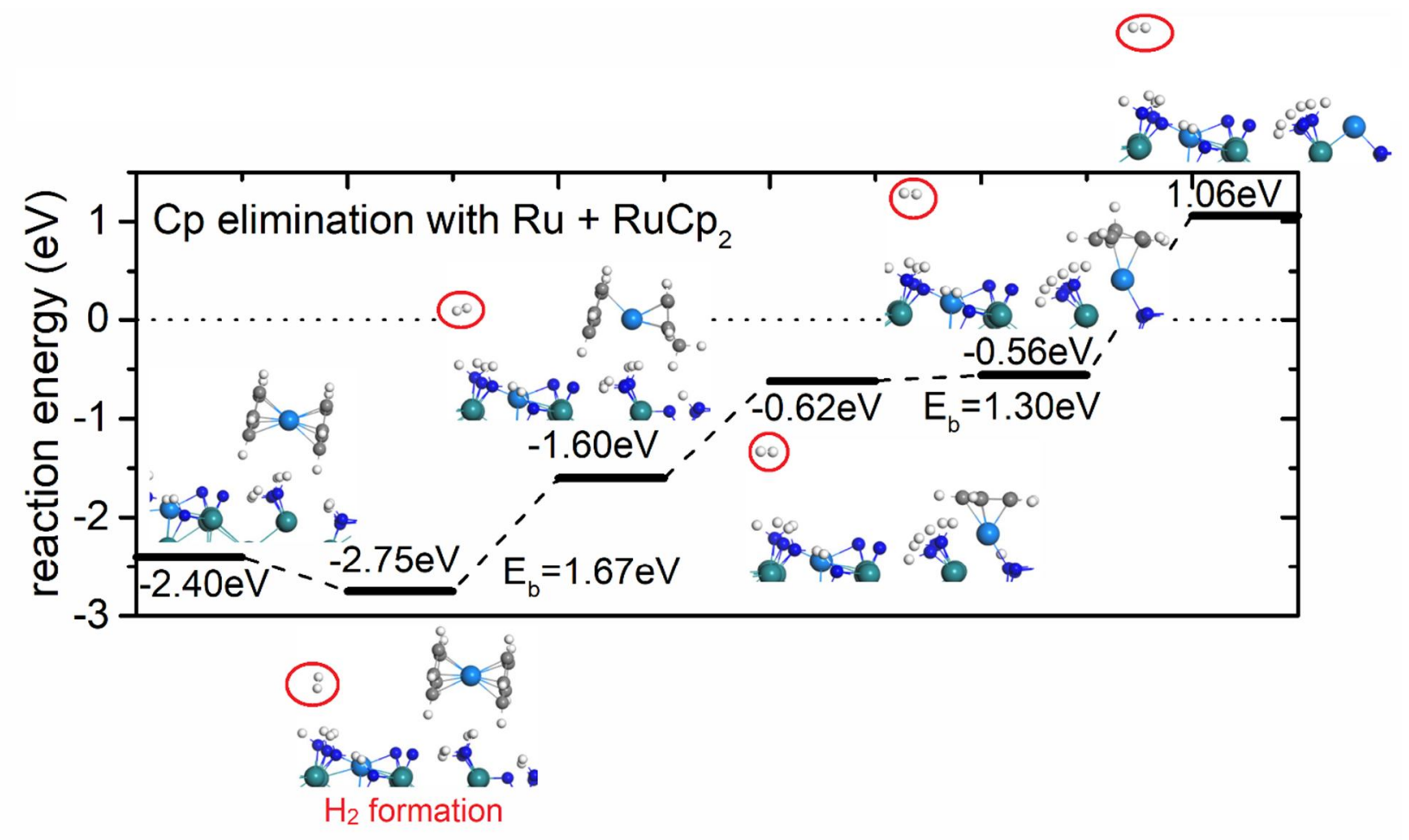

Figure 7. The plotted reaction pathway for $\mathrm{Cp}$ ligand elimination with one deposited $\mathrm{Ru}$ and $\mathrm{RuCp}_{2}$ on $\mathrm{Ru}(100)$ surface. There is $\mathrm{H}_{2}$ formation before hydrogen transfer step. The $\mathrm{Ru}$ atoms are represented by green spheres. Carbon, nitrogen and hydrogen atoms are represented by grey, blue and white colour, respectively.

The computed activation barriers for $\mathrm{H}$ transfer for single $\mathrm{RuCp}_{2}$ precursor, two surface bound $\mathrm{RuCp}_{2}$ species, and one precursor with a bare $\mathrm{Ru}$ atom $\mathrm{Ru}+\mathrm{RuCp} \mathrm{p}_{2}$ on $\mathrm{Ru}(100)$ surface are summarized in Table 6 . We see that the activation barriers for $\mathrm{Cp}$ elimination via hydrogen transfer steps of single $\mathrm{RuCp}_{2}$ and two $\mathrm{RuCp}_{2}$ have no difference. For one precursor with bare $\mathrm{Ru}$ atom deposited on the surface $\mathrm{Ru}+\mathrm{RuCp} 2$, the barrier of first hydrogen transfer is reduced, but it is slightly increased for the second hydrogen transfer. The first hydrogen transfer is the rate-limiting step, which has higher activation barriers than the second hydrogen transfer. Assuming that the 
initial activation barrier for the first hydrogen transfer can be overcome, the final structures can be determined.

Table 6. The calculated activation barriers for first and second hydrogen steps on $\mathrm{NH}_{\mathrm{x}}{ }^{-}$ terminated $\mathrm{Ru}(100)$ surface with one precursor $\mathrm{RuCp}_{2}$, two precursors $\mathrm{RuCp}_{2}+\mathrm{RuCp}_{2}$, and one precursor and one $\mathrm{Ru}$ atom deposited on the surface $\mathrm{Ru}+\mathrm{RuCp}_{2}$.

\begin{tabular}{lccc}
\hline & \multicolumn{3}{c}{ Barriers/eV } \\
& $\mathrm{RuCp}_{2}$ & $\mathrm{RuCp}_{2}+\mathrm{RuCp}_{2}$ & $\mathrm{Ru}+\mathrm{RuCp}_{2}$ \\
\hline $1^{\text {st }}$ hydrogen transfer & 2.01 & 2.02 & 1.67 \\
$2^{\text {nd }}$ hydrogen transfer & 1.00 & 1.01 & 1.30 \\
\hline
\end{tabular}

\subsection{Final structures after metal precursor pulse on $R u(001)$ and (100) surfaces at ALD} operating condition

On $\mathrm{Ru}(001)$ surface, the $\mathrm{NH}_{\mathrm{x}}$-termination is $14 \mathrm{NH}$ at ALD operating condition. At most one $\mathrm{Cp}$ ligand is eliminated via hydrogen transfer, which depends on the condition that the activation barrier $(1.51 \mathrm{eV})$ can be overcome. With the presence of this RuCp fragment, any further Cp ligand via hydrogen transfer is not favoured due to positive reaction energy. At higher temperatures, the surface NH saturation coverage will be further reduced. ${ }^{38}$ To examine this, we have calculated the reaction energy difference $(\Delta \mathrm{E})$ for the first hydrogen transfer step at different NH coverage on $\mathrm{Ru}(001)$ surface and these are summarized in Table 7.

On the $\mathrm{Ru}(001)$ surface, the zero-K surface termination is $1 \mathrm{ML}$ NH. If the temperature is increased to ALD operating condition (temperature range $550 \mathrm{~K}$ to $650 \mathrm{~K}$ ), the surface termination will be 
reduced to $0.89 \mathrm{ML}$ NH. Now, we continue decreasing the coverage and set the surface termination of $\mathrm{Ru}(001)$ at $0.50 \mathrm{ML} \mathrm{NH}, 0.25 \mathrm{ML} \mathrm{NH}$ and $0.06 \mathrm{ML} \mathrm{NH}$. The calculated reaction energy still remains positive for all coverages studied, and we can infer a continued high barrier for the first hydrogen transfer step, which is irrespective of the coverage of the NH surface termination. Thus, at most only one $\mathrm{Cp}$ ligand is eliminated, while the nature of the $\mathrm{NH}_{\mathrm{x}}$-termination has little effect on the elimination of the $\mathrm{Cp}$ ligand on $\mathrm{Ru}(001)$ surface. The final terminations after metal precursor pulse on $\mathrm{Ru}(001)$ surface at ALD operating condition is single RuCp fragment if the activation barrier for the first hydrogen transfer step can be overcome.

Table 7. The calculated reaction energy difference $(\Delta \mathrm{E})$ hydrogen transfer step on $\mathrm{Ru}(001)$ surface with various $\mathrm{NH}_{\mathrm{x}}$-terminations.

\begin{tabular}{lccccc}
\hline $\mathrm{Ru}(001)$ & & & & ALD & Zero-K \\
& & & & \multicolumn{3}{c}{ Temperature } \\
& & & & & \\
\hline & $0.06 \mathrm{ML} \mathrm{NH}$ & $0.25 \mathrm{ML} \mathrm{NH}$ & $0.50 \mathrm{ML} \mathrm{NH}$ & $0.88 \mathrm{ML}$ NH & $1 \mathrm{ML} \mathrm{NH}$ \\
$\Delta \mathrm{E} / \mathrm{eV}$ & 1.51 & 1.68 & 1.69 & 1.50 & 1.48 \\
\hline
\end{tabular}

On the $\mathrm{Ru}(100)$ surface, the channel hydrogen atoms are involved in the hydrogen transfer steps and the two $\mathrm{Cp}$ ligands are eliminated via hydrogen transfer, $\mathrm{CpH}$ formation and desorption. At ALD operating condition, the $\mathrm{NH}_{\mathrm{x}}$-termination is $6 \mathrm{NH}+6 \mathrm{NH}_{2}$. There is $\mathrm{H}_{2}$ formation during the $\mathrm{Cp}$ ligand elimination via hydrogen transfer. Thus, at most two Ru atoms are deposited on the surface, which depends on the condition that the high activation barrier $(-2.01 \mathrm{eV})$ for the first hydrogen transfer can be overcome. 
The final structure on $\mathrm{Ru}(001)$ surface is $\mathrm{RuCp}$ fragment on the surface with the coverage of 0.85 $\mathrm{RuCp} / \mathrm{nm}^{2}$. The final structure on $\mathrm{Ru}(100)$ surface shows $\mathrm{Ru}$ atoms deposited on the surface with the coverage of $2.02 \mathrm{Ru} / \mathrm{nm}^{2}$. These structures are shown in Figure 8 .

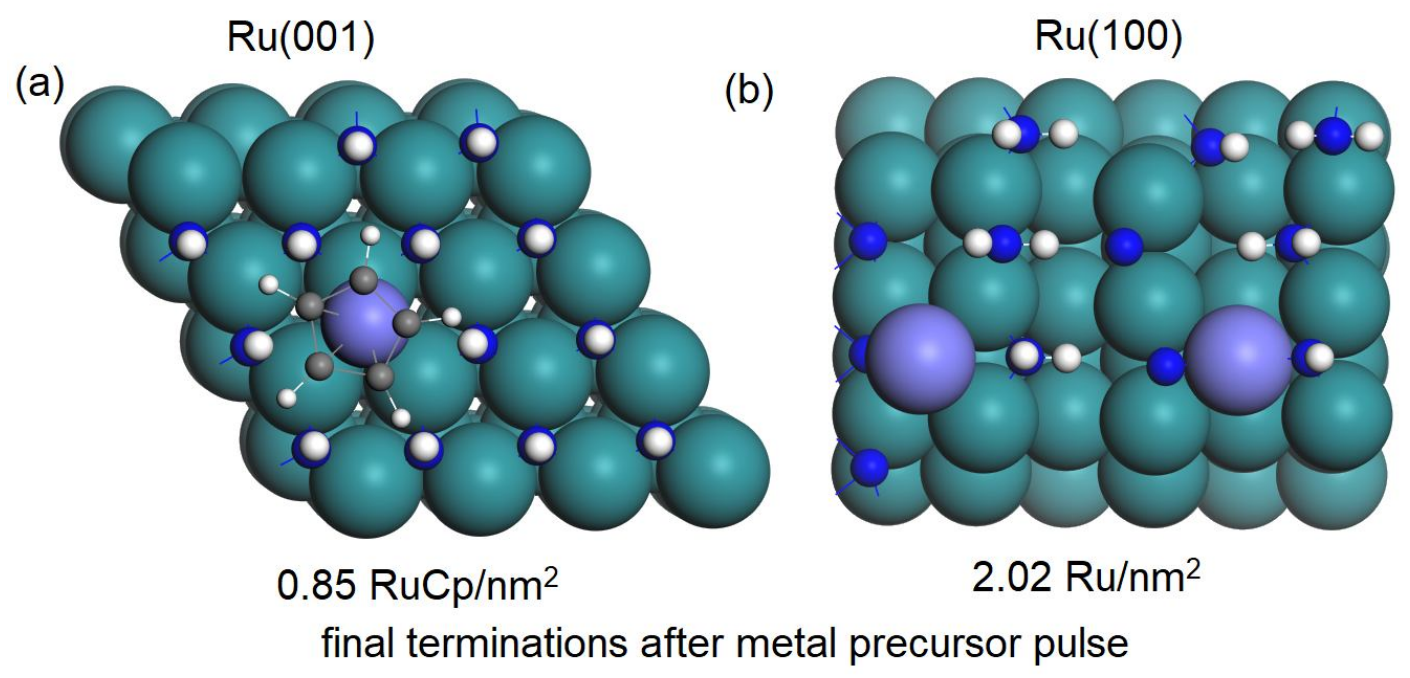

Figure 8. The configurations of final terminations after metal precursor pulse on $\mathrm{Ru}(001)$ and (100) surface. The substrate Ru atoms are represented by green spheres and $\mathrm{Ru}$ atoms from metal precursor are represented by purple spheres. Carbon, nitrogen and hydrogen atoms are represented by grey, blue and white colour, respectively.

\section{Discussion}

\subsection{Effect of surface orientation on the deposition of Ru}

The deposited $\mathrm{Ru}$ thin film is crystalline with hexagonal structure. The orientation is random at low temperature. However, the [001] direction will dominate at elevated temperature or increased plasma power. ${ }^{9}$ Deposition of $\mathrm{Ru}$ on substrates including $\mathrm{TaN}, \mathrm{Si}$ and $\mathrm{SiO}_{2}$ with PE-ALD shows no nucleation delay in contrast to thermal Ru ALD. ${ }^{16} \mathrm{RuCp}_{2}$ has been commonly used as Ru ALD 
precursor experimentally. For the thermal ALD growth, the reported growth rate is $0.45 \square /$ cycle with $\mathrm{RuCp}_{2}$ and oxygen as the reactant. ${ }^{46} \mathrm{PE}-\mathrm{ALD}$ can significantly reduce the incubation time. ${ }^{13}$ The most commonly used precursor for $\mathrm{PE}-\mathrm{ALD}$ of $\mathrm{Ru}$ is $\mathrm{Ru}(\mathrm{EtCp})_{2}$. The reported growth rate varies from $0.16 \square$ /cycle to $0.80 \square /$ cycle, depending on the process condition such as reactor temperature (temperature range $100{ }^{\circ} \mathrm{C}$ to $\left.300{ }^{\circ} \mathrm{C}\right)$ and plasma conditions $\left(\mathrm{N}_{2} / \mathrm{H}_{2}\right.$ plasma and $\mathrm{NH}_{3}$ plasma). ${ }^{13}$ For example, Kwon et al. have reported a GPC at $0.38 \AA /$ cycle using Ru(EtCp $)_{2}$ and $\mathrm{NH}_{3}$ plasma at $270{ }^{\circ} \mathrm{C} .{ }^{14} \mathrm{~N}_{2} / \mathrm{H}_{2}$ plasma can reduce the temperature to $200{ }^{\circ} \mathrm{C}$ and the $\mathrm{GPC}$ remains the same at $0.39 \square /$ cycle. $^{47}$ The growth does not depend significantly on the plasma ambient given that there are $\mathrm{NH}_{\mathrm{x}}$ species.

Theoretically, Phung et al. ${ }^{26}$ have studied the deposition process of $\mathrm{Ru}$ on bare $\mathrm{Ru}$ surface with $\mathrm{RuCp}_{2}$ and $\mathrm{H}_{2}$ plasma. During the metal precursor pulse, $\mathrm{RuCp}_{2}$ can perform dehydrogenation and ligand-dissociation process on bare $\mathrm{Ru}$ surface. They concluded that the growth on $\mathrm{Ru}(001)$ surface should be slow due to weak adsorption of $\mathrm{RuCp}_{2}$. The surface terminations play an important role. They found that the presence of $\mathrm{H}$ on $\mathrm{Ru}$ surface after $\mathrm{H}$ plasma step can inhibit the growth of Ru. Thus, increasing the operating temperature can result in more available surface sites and increase the growth rate, which explains the experimental observed higher growth rate at elevated temperature.

In this study, we start with $\mathrm{NH}_{\mathrm{x}}$-terminated $\mathrm{Ru}$ surface ${ }^{38}$ and the $\mathrm{Cp}$ ligand is eliminated via hydrogen transfer step. We see that the Cp ligand elimination via hydrogen transfer is endothermic and has high activation barriers on $\mathrm{Ru}(001)$ surface. The nature of the $\mathrm{NH}_{\mathrm{x}}$-termination has little effect on the elimination of the $\mathrm{Cp}$ ligand on $\mathrm{Ru}(001)$ surface. At most only one $\mathrm{Cp}$ ligand is eliminated, resulting RuCp fragment after metal precursor pulse at the coverage of $0.85 \mathrm{RuCp} / \mathrm{nm}^{2}$. The growth of $\mathrm{Ru}$ on $\mathrm{NH}_{\mathrm{x}}$-terminated $\mathrm{Ru}(001)$ surface would be limited, which is similar to the 
results of limited growth on bare $\mathrm{Ru}(001)$ surface from Phung's work ${ }^{26}$ and would show a higher growth rate with temperature.

On $\mathrm{Ru}(100)$ surface, the two $\mathrm{Cp}$ ligands of $\mathrm{RuCp}_{2}$ are eliminated completely, depending on the condition that the high activation barrier of the first hydrogen transfer can be overcome. Due to surface $\mathrm{H}_{2}$ formation during the reaction, at most two $\mathrm{Ru}$ atoms are deposited on $\mathrm{Ru}(100)$ surface, resulting a final coverage of $2.02 \mathrm{Ru} / \mathrm{nm}^{2}$. The orientation and surface termination of deposited $\mathrm{Ru}$ therefore impacts on the growth rate. This is one reason why the experimentally reported GPC varies with operating temperatures and Ru metal precursors. ${ }^{13,26}$

From our previous theoretical study ${ }^{37}$ on deposition of Co with $\mathrm{CoCp}_{2}$, on $\mathrm{Co}(001)$ surface, a neighbouring $\mathrm{CoCp}_{2}$ promotes the hydrogen transfer step by reducing the activation barriers. The overall computed activation barriers for $\mathrm{Co}$ are moderate. The final terminations are 3.03 $\mathrm{CoCp} / \mathrm{nm}^{2}$ on $\mathrm{Co}(001)$ surface and $3.33 \mathrm{Co} / \mathrm{nm}^{2}$ on $\mathrm{Co}(100)$ surface. However, the ligand elimination on $\mathrm{Ru}(001)$ surface via hydrogen transfer is limited. We can predict that the orientation of deposited metals has moderate effect on the growth rate of Co, but the growth rate of Ru depends significantly on the orientation.

\subsection{Reactions of the surface bound $\mathrm{NH}_{x}$ species on $\mathrm{Ru}(100)$ surface at the end of first half cycle}

In the following $\mathrm{N}$-plasma step, we expect any $\mathrm{Cp}$ ligands bound to $\mathrm{Ru}$ and surface $\mathrm{NH}_{\mathrm{x}}$ species will be eliminated with plasma radicals $\mathrm{N}, \mathrm{H}, \mathrm{NH}$ and $\mathrm{NH}_{2}$. The study of the plasma step is beyond the scope of this paper. However, we can explore some possible reactions of the surface bound $\mathrm{NH}_{\mathrm{x}}$ species after $\mathrm{CpH}$ desorption on $\mathrm{Ru}(100)$ surface. 
The structure of these surface bound $\mathrm{NH}_{\mathrm{x}}$ species after $\mathrm{CpH}$ desorption on $\mathrm{Ru}(100)$ surface is shown in Figure 9(a). The channel $\mathrm{NH}_{\mathrm{x}}$ species contain 5 bare $\mathrm{N}$ atoms and $1 \mathrm{NH}$ species. The surface $\mathrm{NH}_{\mathrm{x}}$ contains $5 \mathrm{NH}_{2}$ species and $1 \mathrm{NH}$ species. The remaining channel $\mathrm{H}$ atom can form $\mathrm{H}_{2}$ with one surface $\mathrm{H}$ atom and the relaxed structure is shown in Figure 9(b). Alternatively, the remaining channel $\mathrm{H}$ atom can transfer to surface site and the surface $\mathrm{NH}$ reverts to $\mathrm{NH}_{2}$, which is shown in Figure 9(c). The calculated energy indicates that the $\mathrm{H}_{2}$ formation and $\mathrm{NH}_{2}$ formation are energetically favoured compared to surface bound $\mathrm{NH}_{\mathrm{x}}$ species.

(a)
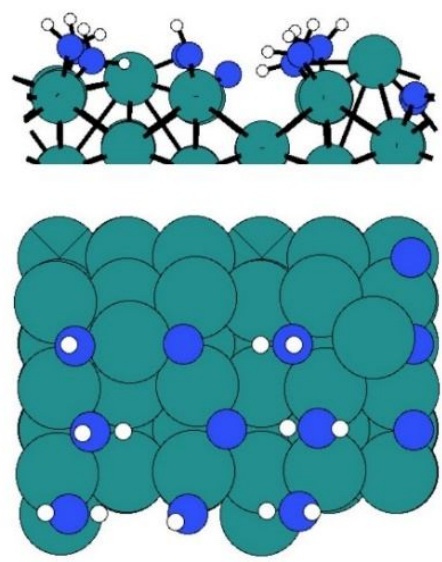

original final structures reference energy (b)
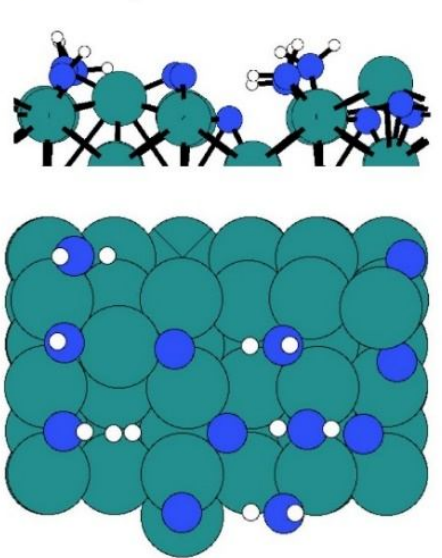

$\mathrm{H}_{2}$ formation $-0.89 \mathrm{eV}$ (c)
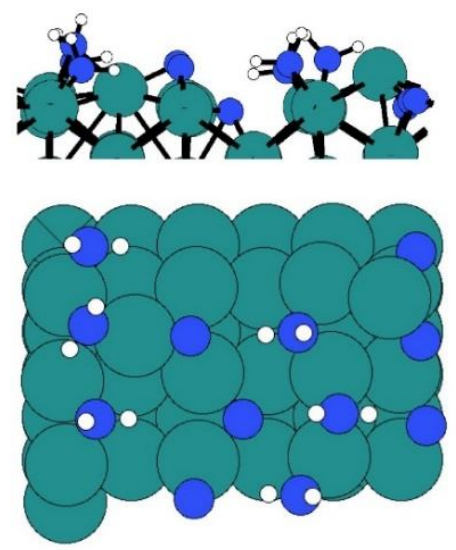

reverts to $\mathrm{NH}_{2}$ $-0.84 \mathrm{eV}$

surface rearragments on $\mathrm{Ru}(100)$ surface

Figure 9. The configurations of surface reactions on the $\mathrm{Ru}(100)$ surface including (a) original final structure of $\mathrm{Ru}$ deposited on $\mathrm{NH}_{\mathrm{x}}$-terminated surface, (b) surface rearrangement via $\mathrm{H}_{2}$ formation, and (c) surface rearrangement via reverting to $\mathrm{NH}_{2}$. The substrate $\mathrm{Ru}$ atoms are represented by green spheres. Nitrogen and hydrogen atoms are represented by blue and white colour, respectively.

After the surface rearrangement, all the channel $\mathrm{H}$ atoms are consumed. We have further investigated the hydrogen transfer step with surface $\mathrm{H}$ atoms. The calculated reaction energies are listed in Table 8. The hydrogen transfer step has a positive reaction energy and is highly 
endothermic. Thus, the surface $\mathrm{H}$ atoms are not involved in $\mathrm{Cp}$ ligand elimination via hydrogen transfer even if all the channel $\mathrm{H}$ atoms are consumed. These surface bound $\mathrm{NH}_{2}$ species and channel $\mathrm{N}$ atoms will likely be removed in the following $\mathrm{N}$-plasma step.

Table 8. The calculated reaction energies for $\mathrm{Cp}$ ligand elimination via surface $\mathrm{H}$ atoms on $\mathrm{Ru}(100)$ surface.

\begin{tabular}{ccc}
\hline & reaction energy/eV & \\
\hline & $\mathrm{H}_{2}$ formation & $\mathrm{NH}_{2}$ formation \\
\hline RuCp 2 adsorption & -0.65 & -0.73 \\
Hydrogen transfer & 1.40 & 1.47 \\
\hline
\end{tabular}

\subsection{Saturation coverages of $R u C p_{2}$ on $R u(001)$ and (100) surfaces}

The discussion of final structures after metal precursor $\mathrm{RuCp}_{2}$ pulse is based on the assumption that the high activation barriers of the first hydrogen transfer on $\mathrm{Ru}(001)$ and (100) surfaces can be overcome through the process temperature. This is due to the strong adsorption strength for $\mathrm{RuCp}_{2}$ on $\mathrm{NH}_{\mathrm{x}}$-terminated $\mathrm{Ru}(001)$ and (100) surfaces. Thus, it is essential to determine the saturation coverages of $\mathrm{RuCp}_{2}$ on these $\mathrm{NH}_{\mathrm{x}}$-terminated $\mathrm{Ru}$ surfaces.

In this study, a ( $4 \times 4)$ supercell is used to simulate $\mathrm{Ru}(001)$ surface while a $(3 \times 3)$ supercell is used to simulate $\mathrm{Ru}(100)$ surface. The calculated surface areas are $1.18 \mathrm{~nm}^{2}$ for $\mathrm{Ru}(001)$ and $0.99 \mathrm{~nm}^{2}$ for $\mathrm{Ru}(100)$. At most four $\mathrm{RuCp}_{2}$ can be placed on $\mathrm{Ru}(001)$ and (100) surfaces. The calculated 
adsorption energies per precursor $\mathrm{RuCp}_{2}$ are shown in Figure 10, which are all exothermic adsorption. These results are summarized on Table 9.

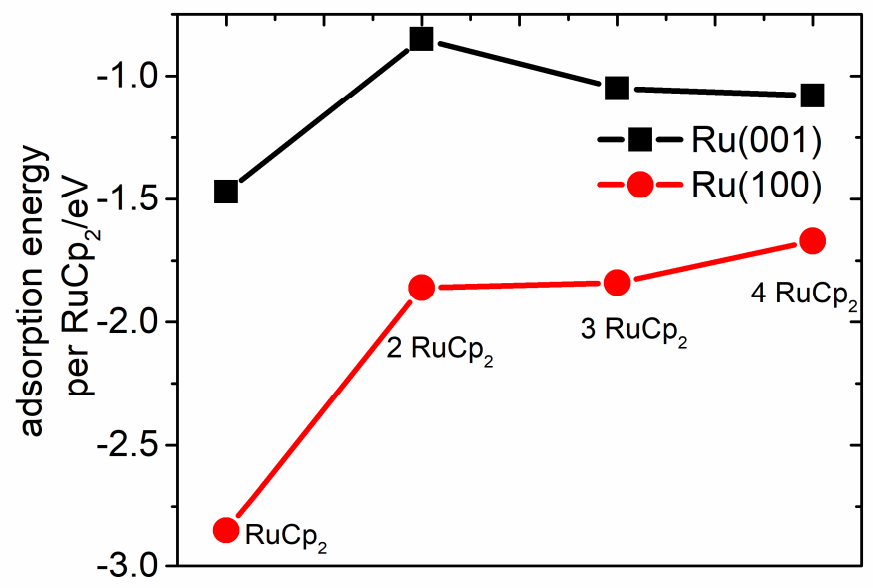

Figure 10. The plotted adsorption energies per $\mathrm{RuCp}_{2}$ on $\mathrm{NH}_{\mathrm{x}}$-terminated $\mathrm{Ru}(001)$ and $\mathrm{Ru}(100)$ surfaces. The $\mathrm{NH}_{\mathrm{x}}$ terminations are at ALD operating condition.

The binding energy difference $\left(\mathrm{BE}_{\mathrm{diff}}\right)$ is computed by

$$
B E_{\text {diff }}=E_{(n+1) R u C p 2}-E_{n R u C p 2}-E_{A}
$$

Table 9. The calculated adsorption energy per RuCp2 and binding energy difference (BE $\mathrm{Bdiff}_{\text {dif }}$ on $\mathrm{Ru}(001)$ and $\mathrm{Ru}(100)$ surfaces.
$\mathrm{RuCp}_{2}$
$2 \mathrm{RuCp}_{2}$
$23 \mathrm{RuCp}_{2}$
$4 \mathrm{RuCp}_{2}$

$\operatorname{Ru}(001)$

$\begin{array}{ccccc}\mathrm{Ead} / \mathrm{eV} & -1.47 & -0.85 & -1.05 & -1.08 \\ \mathrm{BE}_{\mathrm{diff}} / \mathrm{eV} & - & -0.23 & -1.47 & -1.15\end{array}$

$\mathrm{Ru}(100)$

$\begin{array}{lllll}\mathrm{Ead} / \mathrm{eV} & -2.85 & -1.86 & -1.84 & -1.67\end{array}$


(a)

(b)
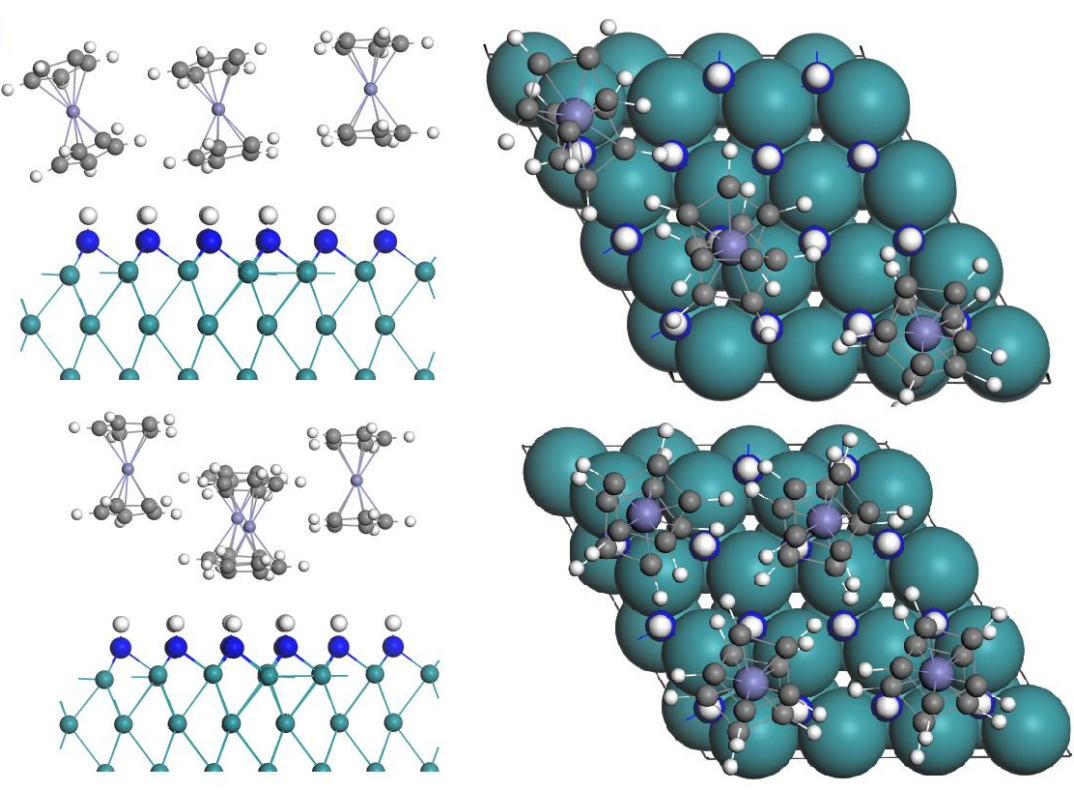

\section{$\mathrm{Ru}(001)$}

(c)
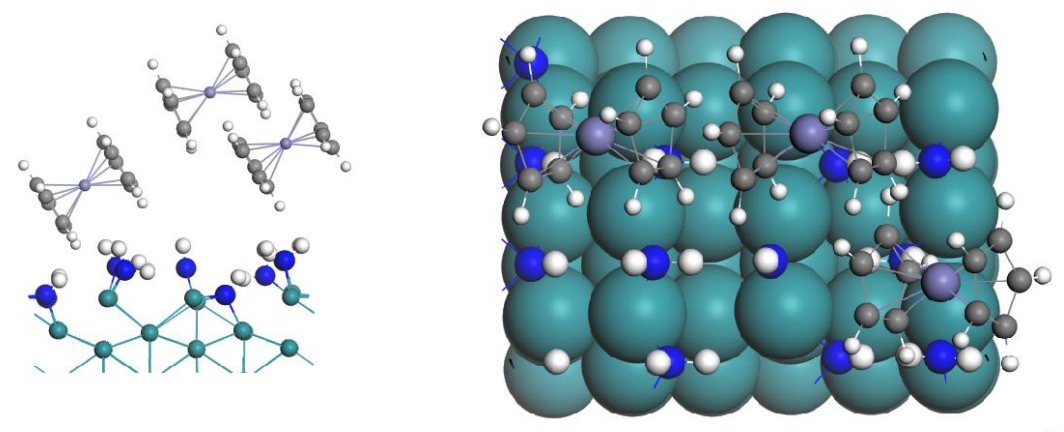

(d)
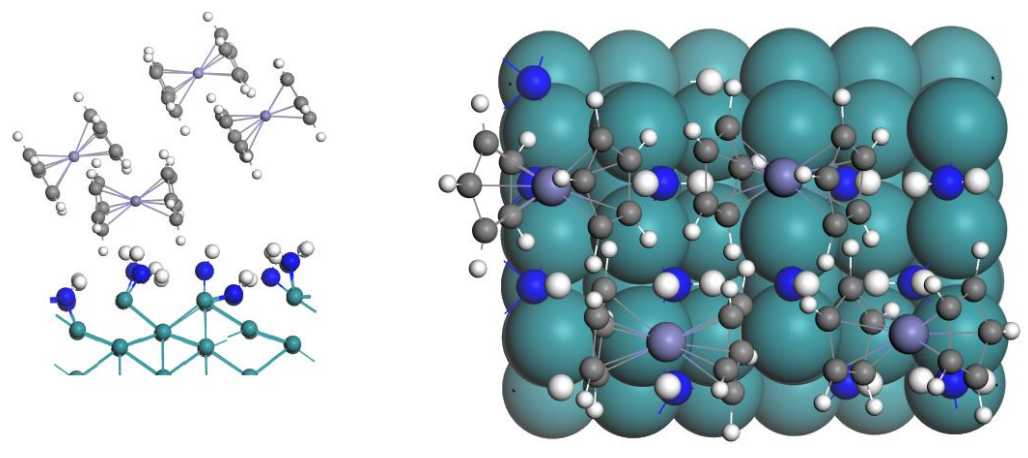

$\mathrm{Ru}(100)$

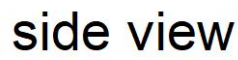

\section{top view}

Figure 11. The side view and top view of $\mathrm{RuCp}_{2}$ adsorption with (a) three $\mathrm{RuCp}_{2}$ on $\mathrm{Ru}(001)$ surface, (b) four $\mathrm{RuCp}_{2}$ on $\mathrm{Ru}(001)$ surface, (c) three $\mathrm{RuCp}_{2}$ on $\mathrm{Ru}(100)$ surface, and four $\mathrm{RuCp}_{2}$ on $\mathrm{Ru}(100)$ surface. The substrate $\mathrm{Ru}$ atoms are represented by green spheres and $\mathrm{Ru}$ atoms from 
metal precursor are represented by purple spheres. Carbon, nitrogen and hydrogen atoms are represented by grey, blue and white colour, respectively.

The structures of adsorbing three $\mathrm{RuCp}_{2}$ and four $\mathrm{RuCp}^{2}$ on $\mathrm{Ru}(001)$ and $\mathrm{Ru}(100)$ surfaces are shown in Figure 11. Although the computed adsorption energy and binding energy difference are all negative, the final stable structures of these adsorbing $\mathrm{RuCp}_{2}$ indicates that on $\mathrm{Ru}(001)$ surface, at most three $\mathrm{RuCp}_{2}$ can be firmly adsorbed, while on $\mathrm{Ru}(100)$ surface, at most only two RuCp 2 can be firmly adsorbed. Thus, the determined maximum coverages of $\mathrm{RuCp}_{2}$ on $\mathrm{Ru}(001)$ and $\mathrm{Ru}(100)$ surfaces are $2.54 \mathrm{RuCp}_{2} / \mathrm{nm}^{2}$ and $2.02 \mathrm{RuCp}_{2} / \mathrm{nm}^{2}$.

\section{Conclusions}

When depositing metals, non-oxidative reactant is preferred because O-source would cause contamination and oxidize metals. The ALD of $\mathrm{Ru}$ using metal precursor $\mathrm{RuCp}_{2}$ and N-plasma have been investigated experimentally but the reaction mechanism is not well-understood. After the $\mathrm{N}$-plasma step, the resulted metal surfaces will be $\mathrm{NH}_{\mathrm{x}}$-terminated. The nature and stability of $\mathrm{NH}_{\mathrm{x}}$-terminated metal surfaces are studied in our previous published work. ${ }^{38}$ This work focuses on the reaction mechanism during the metal precursor pulse. The surface facets will result in different precursor adsorption orientation. $\mathrm{RuCp}_{2}$ prefer upright position with one $\mathrm{Cp}$ ring in close contact with $\mathrm{NH}_{\mathrm{x}}$-terminated $\mathrm{Ru}(001)$ surface, while they are in horizontal position with both of the $\mathrm{Cp}$ rings anchored to zigzag channel on $\mathrm{NH}_{\mathrm{x}}$-terminated $\mathrm{Ru}(100)$ surface.

The $\mathrm{Cp}$ ligands are eliminated via hydrogen transfer step and desorb from surface by forming $\mathrm{CpH}$. On $\mathrm{Ru}(001)$ surface, $1 \mathrm{ML} \mathrm{NH}$ is preferred on $\mathrm{Ru}(001)$ surface at zero-K. With increasing temperature, $\mathrm{NH}$ will gradually desorb from surface, resulting in $0.89 \mathrm{ML}$ NH at ALD operating 
condition. The hydrogen transfer reaction on $\mathrm{Ru}(001)$ surface is endothermic and the barrier is as high as $1.33 \mathrm{eV}$ and $1.51 \mathrm{eV}$ for $1 \mathrm{ML}$ NH termination and $0.89 \mathrm{ML} \mathrm{NH}$ termination. Continuing decreasing $\mathrm{NH}$ coverage to extremely condition with $0.06 \mathrm{ML} \mathrm{NH}$ (one $\mathrm{NH}$ on $(4 \times 4)$ supercell) leads to the similar positive reaction energy difference and at least moderate barrier. The nature of the $\mathrm{NH}_{\mathrm{x}}$-termination and the coverage of adsorbed precursor $\mathrm{RuCp}_{2}$ have little effect on the elimination of the $\mathrm{Cp}$ ligand on $\mathrm{Ru}(001)$ surface. At most only one $\mathrm{Cp}$ ligand is eliminated, resulting RuCp fragment after metal precursor pulse at the coverage of $0.85 \mathrm{RuCp} / \mathrm{nm}^{2}$.

On $\mathrm{Ru}(100)$ surface, two $\mathrm{Cp}$ ligands are eliminated via hydrogen transfer step. For single $\mathrm{RuCp}_{2}$ adsorbed on $\mathrm{NH}_{\mathrm{x}}$-terminated $\mathrm{Ru}(100)$ surface, the barriers for the first and second hydrogen transfer are $2.01 \mathrm{eV}$ and $1.00 \mathrm{eV}$, respectively. For two adsorbed $\mathrm{RuCp}_{2}$ on $\mathrm{NH}_{\mathrm{x}}$-terminated $\mathrm{Ru}(100)$ surface, the barriers barely change, which are $2.02 \mathrm{eV}$ and $1.01 \mathrm{eV}$ for the first and second hydrogen transfer steps. In addition, there is $\mathrm{H}_{2}$ formation during the reaction. This is important for the removal of surface $\mathrm{NH}_{\mathrm{x}}$ species. At most two $\mathrm{Ru}$ atoms are deposited on $\mathrm{Ru}(100)$ surface, resulting a final coverage of $2.02 \mathrm{Ru} / \mathrm{nm}^{2}$.

The metal precursor $\mathrm{RuCp}_{2}$ has strong adsorption strength on $\mathrm{NH}_{\mathrm{x}}$-terminated $\mathrm{Ru}(001)$ and (100) surface. The computed activation barriers for the first hydrogen transfer are high on both (001) and (100) surface. This is irrespective of the coverage of surface adsorbed RuCp 2 . The computed maximum coverages are $2.54 \mathrm{RuCp} 2 / \mathrm{nm}^{2}$ for $\mathrm{Ru}(001)$ and $2.02 \mathrm{RuCp} 2 / \mathrm{nm}^{2}$ for $\mathrm{Ru}(100)$. These adsorbing $\mathrm{RuCp}_{2}$ or remaining $\mathrm{RuCp}$ fragment are eliminated by $\mathrm{N}_{\mathrm{x}} \mathrm{H}_{\mathrm{y}}$ radicals from the $\mathrm{N}$-plasma $\left(\mathrm{NH}_{3}\right.$ or mixture of $\mathrm{N}_{2}$ and $\left.\mathrm{H}_{2}\right)$ in the second half cycle. 


\section{Acknowledgements}

We acknowledge generous support from Science Foundation Ireland (SFI) through the SFI-NSFC Partnership program, Grant Number 17/NSFC/5279, NITRALD and National Natural Science

Foundation of China, Grant number 51861135105. Computing resources have been generously supported by Science Foundation Ireland at Tyndall and through the SFI/HEA-funded Irish Centre for High End Computing (www.ichec.ie).

\section{References}

1. Yim, S.-S.; Lee, D.-J.; Kim, K.-S.; Kim, S.-H.; Yoon, T.-S.; Kim, K.-B., Nucleation kinetics of Ru on silicon oxide and silicon nitride surfaces deposited by atomic layer deposition. J. Appl. Phys. 2008, 103, 113509.

2. Kim, S.; Duquette, D. J., Effect of chemical composition on adhesion of directly electrodeposited copper film on TiN. J. Electrochem. Soc. 2006, 153, C417.

3. Johnson, R. W.; Hultqvist, A.; Bent, S. F., A brief review of atomic layer deposition: from fundamentals to applications. Mater. Today 2014, 17, 236-246.

4. Kaloyeros, A. E.; Pan, Y.; Goff, J.; Arkles, B., Review-Cobalt Thin Films: Trends in Processing Technologies and Emerging Applications. ECS J. Solid State Sci. 2019, 8, P119-P152.

5. Josell, D.; Wheeler, D.; Witt, C.; Moffat, T. P., Seedless superfill: Copper electrodeposition in trenches with ruthenium barriers. Electrochem. Solid State Lett. 2003, 6, C143.

6. Han, J. H.; Lee, S. W.; Choi, G.-J.; Lee, S. Y.; Hwang, C. S.; Dussarrat, C.; Gatineau, J., Chemical vapor deposition of Ru thin films with an enhanced morphology, thermal stability, and electrical properties using a RuO4 precursor. Chem. Mater. 2009, 21, 207-209.

7. George, S. M., Atomic layer deposition: an overview. Chem. Rev. 2009, 110, 111-131.

8. Profijt, H.; Potts, S.; Van de Sanden, M.; Kessels, W., Plasma-assisted atomic layer deposition: basics, opportunities, and challenges. J. Vac. Sci. Technol. A 2011, 29, 050801.

9. Miikkulainen, V.; Leskelä, M.; Ritala, M.; Puurunen, R. L., Crystallinity of inorganic films grown by atomic layer deposition: Overview and general trends. J. Appl. Phys. 2013, 113, 2. 
10. Kwon, S.-H.; Kwon, O.-K.; Kim, J.-H.; Jeong, S.-J.; Kim, S.-W.; Kang, S.-W., Improvement of the morphological stability by stacking $\mathrm{RuO} 2$ on ru thin films with atomic layer deposition. J. Electrochem. Soc. 2007, 154, H773-H777.

11. Ramos, K. B.; Saly, M. J.; Chabal, Y. J., Precursor design and reaction mechanisms for the atomic layer deposition of metal films. Coordin. Chem. Rev. 2013, 257, 3271-3281.

12. Cwik, S.; Woods, K. N.; Saly, M. J.; Knisley, T. J.; Winter, C. H., Thermal atomic layer deposition of ruthenium metal thin films using nonoxidative coreactants. J. Vac. Sci. Technol. A 2020, 38, 012402.

13. Swerts, J.; Delabie, A.; Salimullah, M.; Popovici, M.; Kim, M.-S.; Schaekers, M.; Van Elshocht, S., Impact of the plasma ambient and the ruthenium precursor on the growth of ruthenium films by plasma enhanced atomic layer deposition. Electrochem. Solid-State Lett. 2012, 1, P19-P21.

14. Kwon, O.-K.; Kwon, S.-H.; Park, H.-S.; Kang, S.-W., Plasma-enhanced atomic layer deposition of ruthenium thin films. Electrochem. Solid State Lett. 2004, 7, C46.

15. Sari, W.; Eom, T.-K.; Kim, S.-H.; Kim, H., Plasma Enhanced Atomic Layer Deposition of Ruthenium Thin Films Using Isopropylmethylbenzene-Cyclohexadiene-Ruthenium and NH3 Plasma. $J$. Electrochem. Soc. 2010, 158, D42.

16. Park, S.-J.; Kim, W.-H.; Maeng, W.; Kim, H., Thermal and plasma enhanced atomic layer deposition ruthenium and electrical characterization as a metal electrode. Microelectron. Eng. 2008, 85, 3944.

17. Hämäläinen, J.; Ritala, M.; Leskelä, M., Atomic Layer Deposition of Noble Metals and Their Oxides. Chem. Mater. 2014, 26, 786-801.

18. Park, S.-J.; Kim, W.-H.; Maeng, W.; Yang, Y.; Park, C.; Kim, H.; Lee, K.-N.; Jung, S.-W.; Seong, W., Effect oxygen exposure on the quality of atomic layer deposition of ruthenium from bis (cyclopentadienyl) ruthenium and oxygen. Thin Solid Films 2008, 516, 7345-7349.

19. Leick, N.; Verkuijlen, R.; Lamagna, L.; Langereis, E.; Rushworth, S.; Roozeboom, F.; Van de Sanden, M.; Kessels, W., Atomic layer deposition of Ru from CpRu (CO) 2 Et using O 2 gas and O 2 plasma. J. Vac. Sci. Technol. A 2011, 29, 021016.

20. Lee, S.-J.; Kim, S.-H., Effects of Annealing on the Properties of Atomic Layer Deposited Ru Thin Films Deposited by $\mathrm{NH}_{3}$ and $\mathrm{H}_{2}$ as Reactants. Thin Solid Films 2016, 612, 122-127.

21. Lee, S.-J.; Kim, S.-H.; Saito, M.; Suzuki, K.; Nabeya, S.; Lee, J.; Kim, S.; Yeom, S.; Lee, D.-J., Plasma-Free Atomic Layer Deposition of $\mathrm{Ru}$ Thin Films Using $\mathrm{H}_{2}$ Molecules as A Nonoxidizing Reactant. J. Vac. Sci. Technol. A 2016, 34, 031509.

22. Gakis, G. P.; Vergnes, H.; Cristiano, F.; Tison, Y.; Vahlas, C.; Caussat, B.; Boudouvis, A. G.; Scheid, E., In situ N2-NH3 plasma pre-treatment of silicon substrate enhances the initial growth and restricts the substrate oxidation during alumina ALD. J. Appl. Phys 2019, 126, 125305. 
23. Minjauw, M. M.; Dendooven, J.; Capon, B.; Schaekers, M.; Detavernier, C., Near room temperature plasma enhanced atomic layer deposition of ruthenium using the $\mathrm{RuO}$ 4-precursor and $\mathrm{H}$ 2plasma. J. Mater. Chem. C 2015, 3, 4848-4851.

24. Musschoot, J.; Xie, Q.; Deduytsche, D.; De Keyser, K.; Longrie, D.; Haemers, J.; Van den Berghe, S.; Van Meirhaeghe, R.; D’Haen, J.; Detavernier, C., Texture of atomic layer deposited ruthenium. Microelectron. Eng. 2010, 87, 1879-1883.

25. Elliott, S. D., Atomic-scale simulation of ALD chemistry. Semicond. Sci. Tech. 2012, 27, 074008.

26. Phung, Q. M.; Pourtois, G.; Swerts, J.; Pierloot, K.; Delabie, A., Atomic Layer Deposition of Ruthenium on Ruthenium Surfaces: A Theoretical Study. J. Phys. Chem. C 2015, 119, 6592-6603.

27. Elliott, S. D.; Dey, G.; Maimaiti, Y., Classification of processes for the atomic layer deposition of metals based on mechanistic information from density functional theory calculations. J. Chem. Phys. 2017, $146,052822$.

28. Phung, Q. M.; Vancoillie, S.; Pourtois, G.; Swerts, J.; Pierloot, K.; Delabie, A., Atomic Layer Deposition of Ruthenium on a Titanium Nitride Surface: A Density Functional Theory Study. J. Phys. Chem. C 2013, 117, 19442-19453.

29. Fang, G.; Xu, L.; Cao, Y.; Li, A., Theoretical design and computational screening of precursors for atomic layer deposition. Coordin. Chem. Rev. 2016, 322, 94-103.

30. Holme, T. P.; Prinz, F. B., Atomic Layer Deposition and Chemical Vapor Deposition Precursor Selection Method Application to Strontium and Barium Precursors. J. Phys. Chem. A 2007, 111, 81478151.

31. Puurunen, R. L., Surface chemistry of atomic layer deposition: A case study for the trimethylaluminum/water process. J. Appl. Phys 2005, 97, 9.

32. Elliott, S.; Scarel, G.; Wiemer, C.; Fanciulli, M.; Pavia, G., Ozone-Based Atomic Layer Deposition of Alumina from TMA: Growth, Morphology, and Reaction Mechanism. Chem. Mater. 2006, 18, 37643773.

33. Langereis, E.; Bouman, M.; Keijmel, J.; Heil, S.; Van de Sanden, M.; Kessels, W., Plasma-assisted $\mathrm{ALD}$ of $\mathrm{Al} 2 \mathrm{O} 3$ at low temperatures: reaction mechanisms and material properties. ECS Trans. 2008, 16, 247-255.

34. Rai, V. R.; Vandalon, V.; Agarwal, S., Surface reaction mechanisms during ozone and oxygen plasma assisted atomic layer deposition of aluminum oxide. Langmuir 2010, 26, 13732-13735.

35. Weckman, T.; Laasonen, K., First principles study of the atomic layer deposition of alumina by TMA-H 2 O-process. Phys. Chem. Chem. Phys. 2015, 17, 17322-17334. 
36. Kwon, D. S.; An, C. H.; Kim, S. H.; Kim, D. G.; Lim, J.; Jeon, W.; Hwang, C. S., Atomic layer deposition of Ru thin films using (2, 4-dimethyloxopentadienyl)(ethylcyclopentadienyl) Ru and the effect of ammonia treatment during the deposition. J. Mater. Chem. C 2020.

37. Liu, J.; Lu, H.; Zhang, D. W.; Nolan, M., Reaction Mechanism of the Metal Precursor Pulse in Plasma-Enhanced Atomic Layer Deposition of Cobalt and the Role of Surface Facets. J. Phys. Chem. C 2020, 124, 11990-12000.

38. Liu, J.; Nolan, M., Coverage and Stability of NHx-Terminated Cobalt and Ruthenium Surfaces: A First-Principles Investigation. J. Phys. Chem. C 2019, 123, 25166-25175.

39. Kresse, G.; Joubert, D., From ultrasoft pseudopotentials to the projector augmented-wave method. Phys. Rev. B 1999, 59, 1758.

40. Perdew, J. P.; Chevary, J. A.; Vosko, S. H.; Jackson, K. A.; Pederson, M. R.; Singh, D. J.; Fiolhais, C., Atoms, molecules, solids, and surfaces: Applications of the generalized gradient approximation for exchange and correlation. Phys. Rev. B 1992, 46, 6671.

41. Perdew, J. P.; Burke, K.; Ernzerhof, M., Generalized gradient approximation made simple. Phys. Rev. Lett. 1996, 77, 3865.

42. Monkhorst, H. J.; Pack, J. D., Special points for Brillouin-zone integrations. Phys. Rev. B 1976, 13, 5188.

43. Maimaiti, Y.; Elliott, S. D., Precursor Adsorption on Copper Surfaces as the First Step during the Deposition of Copper: A Density Functional Study with van der Waals Correction. J. Phys. Chem. C 2015, 119, 9375-9385.

44. Henkelman, G.; Uberuaga, B. P.; Jónsson, H., A climbing image nudged elastic band method for finding saddle points and minimum energy paths. J. Chem. Phys. 2000, 113, 9901-9904.

45. Cluff, K. J.; Blümel, J., Adsorption of Metallocenes on Silica. Chem. Eur. J 2016, 22, 16562-16575.

46. Aaltonen, T.; Alén, P.; Ritala, M.; Leskelä, M., Ruthenium thin films grown by atomic layer deposition. Chem. Vap. Depos. 2003, 9, 45-49.

47. Kwon, S.-H.; Kwon, O.-K.; Min, J.-S.; Kang, S.-W., Plasma-enhanced atomic layer deposition of Ru-TiN thin films for copper diffusion barrier metals. J. Electrochem. Soc. 2006, 153, G578. 